\title{
Análisis territorial del crecimiento y la crisis del sector de la construcción en España y la Comunidad Autónoma de Andalucía
}

\author{
Alfonso Fernández-Tabales. Universidad de Sevilla, Sevilla, España. \\ Estrella Cruz. Universidad de Sevilla, Sevilla, España.
}

RESUMEN | España representa un caso excepcional a escala mundial de crecimiento del sector de la construcción y subsector de la vivienda desde los últimos años del siglo pasado hasta 2007, a partir del cual el sector se paraliza y arrastra al conjunto de la economía española. Se presentan los principales rasgos y datos del proceso, así como un diagnóstico de sus factores explicativos. Territorialmente se desciende al caso de Andalucía, donde el fenómeno ha sido especialmente intenso. La metodología se basa en la selección, desarrollo y aplicación de indicadores estadísticos, a escala provincial para el caso español y comarcal para el andaluz. Los resultados son presentados cartográficamente y valorados según la incidencia en los territorios. Finalmente, la discusión se centra en el comportamiento de los distintos territorios ante el fenómeno. Al respecto, es posible confirmar que aquellos que con mayor intensidad se han orientado hacia la construcción han sido posteriormente los más afectados por la crisis, y plantear el peligro de que el proceso pueda reiniciarse en el futuro.

PALABRAS CLAVE | mercado inmobiliario, expansión urbana, crisis económica.

\begin{abstract}
The construction and housing sector has been very important in Spain, and was an exceptional case of growth of the economy in the country up to 2007, when the world crisis began and the Spanish economy fell sharply. The main characteristics, data, and a diagnostic of the process before and during the crisis are analysed in this paper. Andalucia, a Spanish autonomous region where the phenomenon has been especially severe, is discussed in depth. The methodology is based on the application of some statistical indicators at provincial and regional scale and the results are presented using cartographic methods to test their incidence in the territory. Finally, the discussion focuses on the places where the phenomenon is more significant. To this regard, it is possible to confirm that territories where the construction sector was more intensive until 2007 are the areas most affected by the crisis, and that there are risks that this process might start over in the future.
\end{abstract}

KEY WORDS | real state market, urban sprawl, economic crisis.

Recibido el 29 de abril de 2011, aprobado el 2 de agosto de 2011

E-mail: Alfonso Fernández, aftabales@us.es | Estrella Cruz, ecruz@us.es

Este artículo es resultado de los trabajos realizados en el Proyecto de Investigación "Gobernanza territorial y conformación espacial de destinos turísticos. Discursos, procesos y dialécticas en diferentes escenarios” (RefCSO 2010-20284), financiado por el Ministerio de Ciencia e Innovación de España. Plan Nacional de I+D+i 2008-2011. 


\section{Introducción}

El artículo tiene como objetivo principal analizar con un enfoque territorial el proceso de crecimiento y posterior crisis del sector de la construcción en España durante la primera década de este siglo. Para acceder a un mayor nivel de detalle en el análisis, se descenderá en escala al caso de la Comunidad Autónoma de Andalucía, donde el fenómeno ha tenido una especial relevancia. Por último, se ofrece una propuesta de indicadores válidos para la territorialización de los procesos, su análisis y la obtención de conclusiones de cara al futuro.

Para todo ello, las preguntas básicas de investigación que se plantean son:

- ¿Constituyen los casos español y andaluz una singularidad científicamente relevante en los escenarios europeo y mundial, debido a los rasgos cuantitativos y cualitativos del proceso de crecimiento y posterior crisis del sector de la construcción?

- ¿Puede afirmarse que una marcada orientación de las estructuras socioeconómicas y territoriales hacia el sector de la construcción, tanto en los ámbitos locales como comarcales, las hace seriamente vulnerables a los cambios de la coyuntura?

- Desde el punto de vista metodológico, ¿resulta adecuado el conjunto de indicadores utilizado para el tratamiento del tema objeto de estudio?

\section{Singularidades cuantitativas y cualitativas del caso español}

La existencia de ciclos económicos vinculados al sector de la construcción no es algo nuevo en la experiencia española. Durante la segunda mitad del siglo XX y principios del XXI, la economía española ha estado marcada por procesos de auge en el sector de la construcción, pese a que las circunstancias sean muy diferentes, según el periodo analizado. El primer boom, caracterizado por la construcción de más de 500.000 viviendas anuales, se registró en la década de 1960, uno de los momentos de mayor crecimiento del sector hasta que empezó la recesión ligada a la primera crisis petrolera de 1973. Tras esa coyuntura, que afectó de manera generalizada a toda Europa, se produjo una nueva fase de expansión en la segunda mitad de los ochenta, un importante crecimiento especulativo y de precios impulsado, en buena parte, por la intensa actividad inversora en infraestructuras que tuvo lugar a partir de la integración de España en la Unión Europea, así como por la inversión en construcción residencial, aunque esta última no superó las 400.000 viviendas anuales (Naredo, 2004; Cuadrado-Roura, 2010).

En la actualidad, la experiencia española presenta, tanto por el acelerado crecimiento del sector de la construcción desde finales del siglo pasado hasta 2007, como por el brusco colapso del mismo en años posteriores, un caso excepcional en el escenario europeo y mundial, así como respecto de las anteriores crisis vividas en el país. Su singularidad se deriva, en primer lugar, de la magnitud y circunstancias que 
han acompañado al último período alcista, mucho más acusadas que las ya vividas en el país hace décadas, como se mostrará más adelante. Un dato muy significativo al respecto es que en el año 2006 se cuantificó una cifra cercana a las 670.000 viviendas libres iniciadas, la más alta del período de auge. En segundo lugar, el caso español es notable por la intensidad del impacto de la crisis financiera que, si bien se inició en el exterior (Estados Unidos), alcanzó en el caso español una virulencia e intensidad que solo pueden explicarse por el inadecuado modelo de crecimiento vigente en el momento (Bernardos, 2009), el cual se ha demostrado insostenible en el tiempo.

La consecuencia actual es que España está experimentando dos crisis superpuestas: la derivada del proceso de ruptura de la burbuja inmobiliaria ocasionada por el modelo de desarrollo económico de la última década; y la generada por la crisis económica financiera internacional, con gran repercusión sobre el sistema bancario nacional y con las conocidas consecuencias de endeudamiento por las que están atravesando el Estado y las Comunidades Autónomas.

El carácter singular de la experiencia española puede ser demostrado a partir de un conjunto de resultados estadísticos (tanto cuantitativos como cualitativos), cuya selección se presenta a continuación.

En primer lugar, desde la mitad de la década de los años noventa hasta el año 2007, la economía española se caracterizó por atravesar un potente ciclo expansivo, con crecimientos anuales del PIB superiores al 3\%, lo que constituye la variación positiva más acusada del PIB respecto del resto de países de la UE-12, hasta que se produjo el cambio de tendencia económica mundial en el año 2008.

Existe actualmente un elevado nivel de coincidencia en la literatura científica (Naredo, 2006; Rodríguez López, 2007; García-Montalvo, 2009) acerca de la notable influencia que ha tenido en este crecimiento la progresiva basculación del modelo económico español hacia el sector de la construcción, pareciendo innegable que el acelerado incremento del peso proporcional del mismo no puede ser ajeno al resultado global. A este respecto, la singularidad del caso español queda bien reflejada en los datos que Eurostat proporciona con relación al volumen de población empleada dedicada a esta actividad económica. Si se realiza este análisis en términos absolutos para el año 2006, España, Italia, Francia, Alemania y Reino Unido son los países que encabezarían el ranking de mayor número de empleados en este sector. ${ }^{1}$ En términos relativos, los resultados son aún más importantes: el $14,17 \%$ de la población española dada de alta en la Seguridad Social estaba empleada en el sector de la construcción, aspecto en que ocupa el segundo lugar después de Luxemburgo (18,29\%). De forma paralela, y como consecuencia directa de la evolución anterior, tras el estallido de la crisis el protagonismo del sector de la construcción en la destrucción de empleos ha sido muy relevante. Así, a modo de ejemplo con los últimos datos conocidos, de la caída de afiliados a la Seguridad Social en 2010, cifrada en 218.857 personas, el 90\% procedía del sector de la construcción (Tesorería General de la Seguridad Social, 2011).

España: 2.797.500, Italia: 1.844.895, Francia: 1.651.546, Alemania: 1.498.760, Reino Unido: 1.393.461. Valores aportados por Eurostat para el año 2006 (unidad: personas). 
El auge del sector de la construcción en los primeros años del siglo se hace patente al compararse su evolución cronológica con la del resto de ramas de la actividad: en datos relativos, tomando el año 2000 como base 100, se observa cómo la construcción aumentó su valor añadido bruto (VAB) en la economía española en 43\% entre los años 2000 y 2007 (Instituto Nacional de Estadística [INE], varios años), siendo con diferencia la actividad que ha experimentado un incremento más acusado en dicho intervalo.

Por otra parte, el sector de la construcción en España presenta una serie de características que lo han diferenciado de la mayoría de los países de la Unión Europea. Una de las más destacables se refiere a que el principal volumen de construcción se ha basado en obra nueva, tanto en vivienda como en obra pública; de esta forma, según datos del Observatorio de la Sostenibilidad de España (2009), el valor más alto de nuevas viviendas construidas se obtuvo en el año 2006, con la cifra de 18.000 viviendas nuevas por cada millón de habitantes, frente a las 5.000 viviendas por cada millón de habitantes de los Estados Miembros de la UE. Según las últimas estadísticas proporcionadas por el Ministerio de la Vivienda, el parque inmobiliario español aumentó en 4.095.448 nuevas viviendas en el período 2001-2008. Igualmente, un dato significativo del parque de viviendas español respecto del resto de países europeos que aparece recogido en el informe Housing Statistics in the European Union (Dol \& Haffner, 2010), es que desde el año 2005 se registran los valores más altos referidos al indicador "número de viviendas por cada mil habitantes" En este sentido, en el año 2008 se cuantificaban en España 544 viviendas por cada mil habitantes, seguida de la ex República Democrática Alemana y Finlandia, con 537 y 531 viviendas por cada mil habitantes, respectivamente (si bien para valorar adecuadamente estos datos hay que tener en cuenta, como se ampliará y precisará en epígrafes posteriores de este artículo, que buena parte de dichas viviendas son residencias secundarias, y que otra parte considerable pertenece a población extranjera que las utiliza una parte del año).

Tras estos años de ingente crecimiento del parque inmobiliario, el descenso de las cifras a partir del cambio de tendencia en 2007 ha resultado de gran brusquedad. En este sentido, resultan muy significativos los datos proporcionados por la Agrupación de Fabricantes de Cementos de España (Oficemen) con relación a la venta de cemento gris, la que pasó de 45.226.394 Tm a 24.578.608 Tm entre los años 2007 y 2009 , esto es, un porcentaje de decrecimiento de 45,65\%.

Igualmente de interés son los datos referidos a viviendas libres iniciadas en España, tal y como se muestra en la gráfica de la Figura 1. Como indican los últimos datos disponibles, el número de viviendas libres iniciadas en 2010 no llega al 10\% de la cifra alcanzada en 2006 (Ministerio de Fomento). De hecho, el dato registrado en 2010 (63.090 viviendas) no encuentra precedentes en la serie estadística de dicho Ministerio, que ofrece datos desde 1990.

Con relación a la demanda de vivienda, es notable la caída experimentada a partir de la segunda mitad de 2007, con un aumento de las diferencias entre las viviendas terminadas y las viviendas vendidas de nueva construcción. En ese contexto, el stock de viviendas terminadas no vendidas aceleró su crecimiento, generando en 2005 un parque aproximado de 200.000 viviendas, el cual ha aumentado hasta al- 
canzar una cifra estimada de 687.523 unidades al 31 de diciembre de 2010 (Ministerio de Fomento, 2011). Esa intensa caída del sector también queda reflejada en las cifras de transacciones de viviendas, las cuales muestran un descenso en las ventas de 53,60\% entre los años 2007 y 2010 en España, según las estadísticas publicadas por el Ministerio de Fomento, reducción que en la Unión Europea solo se ha visto superada por el caso irlandés (-68,21\%) (Dol \& Haffner, 2010). Otro indicador de interés que refleja la caída del sector es el referido a los precios de la vivienda libre, los cuales han experimentado una variación negativa de 15,40\% entre los primeros trimestres de 2008 y 2011.

FIGURA 1 Número de viviendas libres iniciadas en España (2004-2010)

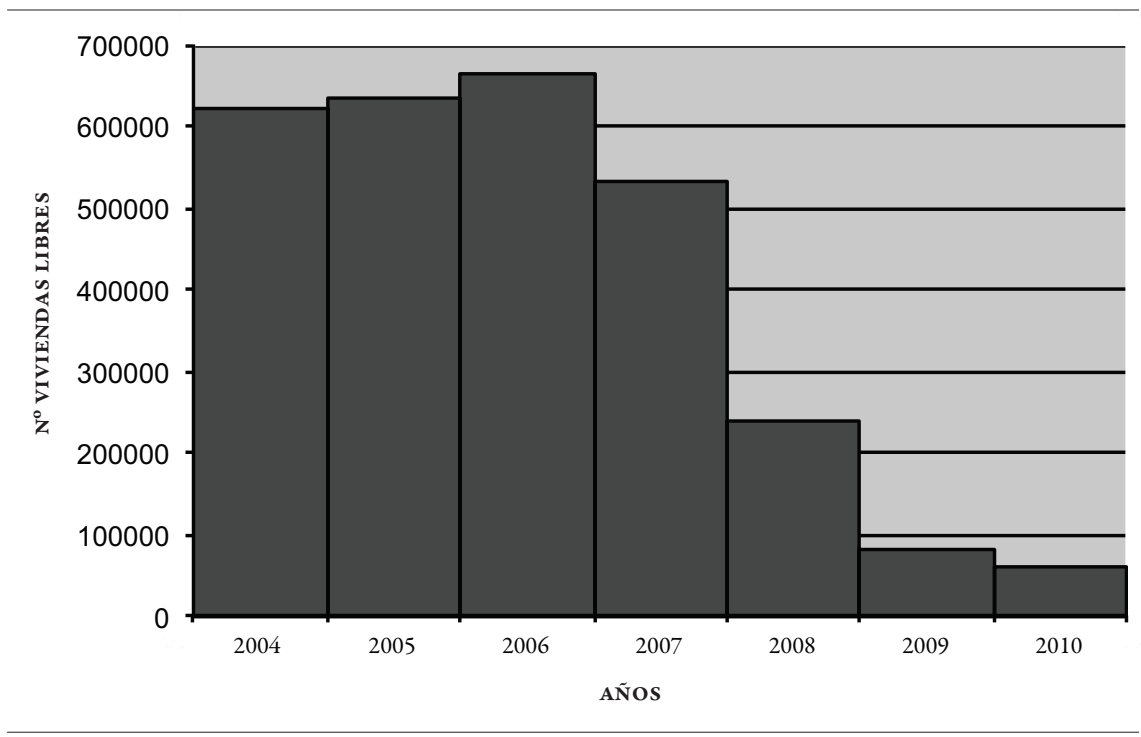

FUeNTE Elaboración Propia a PARTir de datos del Ministerio de Fomento.

\section{Síntesis de factores explicativos del proceso}

Un proceso que registra las magnitudes anteriormente expuestas difícilmente puede ser generado por un solo factor o un conjunto simple de los mismos. En efecto, en este caso puede percibirse una compleja e intrincada red de causas interrelacionadas, cuyo tratamiento requiere un enfoque transdisciplinar. A continuación, y con las salvedades señaladas, se ofrece una síntesis de dichas causas, estructuradas temáticamente.

\section{Causas financieras}

En el mercado residencial, las entidades financieras tienen el decisivo papel de proporcionar financiación para la adquisición de suelo, construcción de inmuebles y compra de viviendas. Estas circunstancias convierten a las entidades financieras en 
agentes determinantes del ciclo inmobiliario, al condicionar la oferta futura y demanda actual de viviendas. De este modo, puede afirmarse que las causas financieras son las que mayor incidencia han ejercido finalmente en la dinámica inmobiliaria, y especialmente en los ritmos del proceso. Destaca poderosamente el muy favorable contexto de bajos tipos de interés imperantes durante el periodo examinado, los cuales han posibilitado unas excelentes condiciones de financiación para la compra de inmuebles (por parte del consumidor final) o para el emprendimiento de proyectos de urbanización y construcción (por parte de los agentes promotores). De hecho, como afirmó ya tempranamente uno de los más prestigiosos especialistas en la materia, "la incidencia expansiva de la baja del tipo de interés sobre la demanda inmobiliaria [en España] aporta un ejemplo modélico de la interacción entre los aspectos financieros y los inmobiliarios" (Naredo, 2002, p. 12). De tal interacción existen abundantes precedentes internacionales que ratifican el diagnóstico, referenciados por la literatura científica: Corea del Sur a finales de los ochenta y principios de los noventa (Kim, 1999); Reino Unido durante los ochenta y siglo actual (Meen, 1996; Hamnett, 2009); Irlanda a finales de los noventa y comienzos de la década siguiente (Stevenson \& Young, 2006); Estados Unidos (Shiller, 2008). Para el caso de España hay también varios estudios de reciente data (García Montalvo, 2009; Rodríguez López, 2009; Taltavull de la Paz, 2010; Pareja-Eastway \& Sánchez-Martínez, 2011).

En efecto, en la primera mitad de la década pasada se han contabilizado en España los tipos de interés más bajos de los últimos cincuenta años (Rodríguez López, 2007, p. 84), con valores establecidos en continuo descenso por el Banco Central Europeo, hasta llegar a situarse entre 2003 y 2005 en torno al 2\%. Tal situación contrasta abiertamente con la década anterior, en la que las tasas hipotecarias alcanzaron en España cifras estables entre el 12\% y el 15\%. A ello se ha unido un incremento notable en los plazos medios de devolución de los préstamos hipotecarios (unos veinticinco años, pero llegando en algunos casos a los cuarenta y hasta a los cincuenta años), la elevación en la relación préstamo/valor y la práctica ausencia de restricciones crediticias. De todo esto puede concluirse que las condiciones del crédito para la adquisición y promoción de vivienda han sido las mejores de la historia de España desde que hay constancia estadística.

Estas condiciones de financiación han sido, asimismo, determinantes para una elevación igualmente histórica del precio de la vivienda (con las consiguientes alzas en los beneficios de los agentes promotores, principal mecanismo dinamizador de la oleada constructiva). Ello se explica por el hecho de que en el mercado de la vivienda el precio del producto no viene determinado por la dialéctica oferta-demanda, o por una voluntad o disposición a pagar un precio (en función de la calidad del producto, hábitos de consumo, etcétera), sino que se establece a partir de la "capacidad límite de pago" de la demanda, elevándose muy por encima de los costes para acercarse al "techo de capacidad adquisitiva de la población" (Ocaña, 2009, p. 358).

A partir de este hecho, es fácil deducir que las históricas condiciones del mercado hipotecario se han traducido en una acusada elevación de la capacidad adquisiti- 
va en amplias capas de la población (medida cotidianamente en la mensualidad que se paga por el préstamo hipotecario), cimentándose así un ingente proceso de adquisición de viviendas, pese a la elevación acelerada de su precio. A ello se une que las condiciones favorables de financiación han sido igualmente disfrutadas por las empresas constructoras y agentes promotores, que de esta forma han podido afrontar con mayor facilidad y menores costes financieros sus operaciones inmobiliarias. De hecho, esta orientación de las entidades financieras españolas hacia el préstamo a la promoción inmobiliaria, no tanto al préstamo a compradores, ha colocado a algunas de ellas en difícil posición tras el colapso del sector en 2008. En los ejemplos más extremos - como en el conocido caso de la Caja de Ahorros de Castilla-La Mancha en marzo de 2009-, se ha llegado a la necesidad de su intervención por el Banco de España, lo que ha obligado a que otras entidades emprendan rápidos procesos de fusión o absorción para evitar similar desenlace.

Por su parte, la coyuntura de bajos tipos de interés, traducida en una escasa rentabilidad de los depósitos bancarios, unida a una reducción del atractivo de las inversiones bursátiles durante el periodo, ha contribuido de forma manifiesta a dirigir la práctica totalidad del ahorro nacional hacia la adquisición de suelo o inmuebles, en los que la revalorización anual por la acelerada subida de precios auspiciaba beneficios notoriamente superiores a los ofrecidos por las restantes formas de inversión. Junto con ello, se ha desincentivado el ahorro (a este respecto, baste recordar que durante más de veinticuatro meses a mediados de la primera década del siglo los tipos hipotecarios descendieron por debajo de la inflación, figurando por tanto a interés neto negativo [Caruana, 2005]), con lo que se alimentó todo el mecanismo expansivo del sector.

En este sentido, cabe destacar como factor explicativo la extensión de la concepción según la cual la vivienda se transforma de bien de uso en bien de inversión, o incluso de especulación. Este hecho - la adquisición de viviendas no tanto con el objetivo de su utilización (ya sea como residencia primaria o secundaria), sino para la obtención de beneficios con su venta posterior- no es en absoluto novedoso ni privativo del caso español (Whitehead, 2006; Norris \& Winston, 2010), pero alcanzó dimensiones espectaculares a mediados de la primera década del siglo en España. La causalidad del mismo ya ha sido en buena parte señalada al tratar de la incidencia de la evolución de los tipos de interés, a lo que cabe añadir el afloramiento de "dinero negro" generado por la entrada en vigor del euro, y la difícilmente demostrable — pero algo más que anecdótica - llegada a España de capitales procedentes de redes internacionales de actividades ilegales. Todo ello permite explicar la presencia de la finalidad inversora, más allá de la lógica demanda de uso, como uno de los principales motores del proceso, con la consiguiente elevación artificial de los precios de la vivienda, que a la vez retroalimenta el mecanismo y casi imposibilita el acceso a la misma de la demanda real, en especial la que busca adquirir el bien inmueble para la formación de nuevos hogares.

En esta dinámica ha tenido particular relevancia lo que algunos autores (Malpezzi \& Wachter, 2005) vienen denominando "comportamiento miope" de los participantes en el mercado de la vivienda, los cuales cifran sobremanera sus expec- 
tativas de beneficio inversor en el historial de precios recientes del sector, confiando en que las tendencias alcistas, evidentes a corto plazo, se sigan manteniendo y les permitan liquidar beneficios mediante la venta del bien antes del estallido de las conocidas "burbujas inmobiliarias" (Stevenson \& Young, 2006). Baste para reflejar la dimensión del fenómeno en España que para finales de 2008 se estimaban en 997.652 las viviendas vacías no vendidas, de las que 449.111 se situaban solo en la costa mediterránea y archipiélago balear (Ministerio de la Vivienda, 2009), como muestra inequívoca del desfase entre oferta y demanda real y de la magnitud de recursos atrapados tras el estallido de la burbuja.

\section{Causas demográfico-productivas}

Los factores demográfico-productivos son los más evidentes — por así decirlo, los más "naturales" - en el incremento del parque de viviendas, y su incidencia en el caso español es fácilmente constatable (si bien no explican la magnitud del fenómeno).

En efecto, durante el final de la década de los noventa y la primera mitad de la siguiente, la economía española presentó tasas de crecimiento del PIB muy notables, superiores al 3\% interanual: ellas alcanzaron, sobre un índice base 100 para el año 2000, una cifra proporcional de 126,1 para el PIB de 2007 (INE, 2009), lo que se tradujo en una mejora generalizada de los niveles de renta y empleo, con un destacable incremento de la población activa. Ello ha significado para grandes contingentes de población la posibilidad de acceder al mercado de la vivienda, bien para la adquisición de una primera residencia, o para cambiar a mejor la anteriormente poseída o incorporar una segunda residencia vacacional. Todo ello, lógicamente, ha dinamizado el sector inmobiliario, con pautas bien conocidas y estudiadas en otros países (Englund \& Ioannides, 1997; Otrok \& Terrones, 2005).

De forma paralela e interrelacionada con lo anterior, se registra un considerable incremento demográfico, impulsado esencialmente por la llegada de inmigrantes, que en la década de 1995 a 2005 se cifró en unos cuatro millones de personas, casi el 10\% de la población total (INE, 2007), en un proceso absolutamente inédito en la historia de España. Este enorme flujo inmigratorio ha presionado de diferentes formas el mercado de viviendas, como corresponde a su propia heterogeneidad: por una parte, los inmigrantes provenientes de países con menor nivel de desarrollo, venidos en busca de trabajo, han ocupado los estratos más bajos de dicho mercado (fundamentalmente alquileres, pero al revitalizar este segmento también cooperan al incremento de los precios y los beneficios del resto del parque inmobiliario; y ello sin despreciar la compra de viviendas por parte de los mejor situados); por otra, están los procedentes de países europeos más desarrollados, en particular jubilados que fijan su residencia en España, cuya singularidad y notable incidencia requieren ser tratadas con mayor detenimiento a continuación.

El fenómeno en sí es bien conocido, siendo el hecho diferencial del caso español las magnitudes alcanzadas y la celeridad con que se ha desarrollado. Consiste en la llegada de población de edad avanzada (de ahí la expresión "gerontoinmigración" con la que ha sido designada), ya jubilada, procedente de países con elevado nivel de desarrollo, 
que adquieren residencias en las zonas litorales y turísticas españolas, si bien progresivamente han ido adentrándose en el interior (Fernández-Tabales \& Mendoza, 2007).

Las motivaciones del proceso son diversas, debiendo citarse entre ellas la confortabilidad climática del litoral español (por ello se los califica también de "inmigrantes climáticos” [Requejo, 2005]), la buena imagen turística de España en esos mercados, la estabilidad monetaria y seguridad jurídica derivadas de la integración en la UE y la Zona Euro, el diferencial de precios de la vivienda, aún favorable a España, la facilidad de desplazamiento a los países de origen gracias a vuelos lowcost, así como la notable mejoría de las comunicaciones interiores españolas; o, por último, la importante seguridad en todos los aspectos (seguridad ciudadana, sistema sanitario, seguridad alimentaria, derechos del consumidor, etcétera) que España ofrece a estas poblaciones de edad avanzada, ventaja competitiva esencial frente a destinos emergentes del Mediterráneo, con mejores precios pero menores niveles de desarrollo socioeconómico y territorial.

Esta realidad obliga a contextualizar cada vez más las coyunturas españolas en el ámbito internacional europeo; es decir, nos enfrentamos a la necesidad de cambiar la escala de diagnóstico de los problemas territoriales que, aunque con decisiva influencia en lo local, encuentran algunos de los principales factores explicativos de su génesis en la escala supranacional. Este hecho, también esencial en todo lo relativo a las fluctuaciones de los tipos de interés, se manifiesta en toda su trascendencia en el factor aquí tratado, con cifras que cabe calificar de espectaculares. Las entradas de capital extranjero para compra de inmuebles en España en los años de mayor auge, así como su correspondencia proporcional con el PIB nacional de los diferentes años, se indican en Cuadro 1.

CUADRO 1 Entradas de capital extranjero para compra de inmuebles en España, 2002-2006

\begin{tabular}{|c|c|c|}
\hline AÑ̃ & $\begin{array}{l}\text { CAPITAL EXTRANJERO PARA COMPRA DE } \\
\text { INMUEBLES EN ESPAÑA (EN EUROS) }\end{array}$ & PORCENTAJE DEL PIB NACIONAL \\
\hline 2002 & 6.043 millones & 0,83 \\
\hline 2003 & 7.072 millones & 0,90 \\
\hline 2004 & 6.650 millones & 0,79 \\
\hline 2005 & 5.495 millones & 0,60 \\
\hline 2006 & 4.766 millones & 0,48 \\
\hline
\end{tabular}

FUENTES BANCO DE ESPAÑA, INE y ELABORACIÓN PROPIA.

Así pues, no es arriesgado afirmar que la demanda exterior, junto con la llegada de capitales de inversión externos al sector inmobiliario, han sido factores determinantes de la oleada urbanizadora y en la elevación de los precios en los últimos años, muy es- 
pecialmente en territorios con fuerte orientación turística, como los litorales de Cataluña, Comunidad Valenciana, Murcia, Andalucía y los archipiélagos canario y balear.

\section{Causas sociales y culturales}

En este ámbito existen dos aspectos que singularizan nítidamente el caso español en el contexto europeo: en primer lugar, la marcada preponderancia de la vivienda en propiedad frente al alojamiento en alquiler; y luego, la extendida presencia de la segunda residencia, de forma que casi el $15 \%$ de los hogares españoles poseía una residencia secundaria en 2001, ya antes de la gran expansión (INE, 2001), cifra que se ha incrementado posteriormente (a este respecto, véase en el apartado relativo al caso andaluz, los resultados del Índice de Función Residencial No Permanente).

Ambos fenómenos comparten algunos factores explicativos comunes, tales como la ya tradicional (desde la década de los cincuenta) política fiscal favorecedora de la adquisición de vivienda (Taltavull de la Paz, 2006; Rodríguez López, 2007), la facilidad crediticia desde los últimos años noventa, o un componente sociológico en el seno de la población española tendiente a orientar buena parte del ahorro familiar hacia los bienes raíces, como inversión de probada seguridad de cara al futuro.

A los anteriores se unen factores específicos de cada fenómeno. En el caso del alquiler, la aparición de legislaciones desde los años noventa que — paradójicamente- han endurecido las condiciones de los inquilinos (Fernández Durán, 2006), o la inexistencia de alquiler público. En el caso de la segunda residencia, el notable impacto y extensión de su concepción como bien de inversión, o la elevada potencialidad turística de buena parte del territorio español, han convertido amplias zonas del interior y casi todo el litoral en "espacios de ocio", ya sea en alojamiento reglado o en residencia secundaria, y todo ello a una isocrona de menos de hora y media de las principales aglomeraciones urbanas (excepto Madrid en lo que respecta al litoral) de donde parte el grueso de su demanda; aspecto este, además, que ha mejorado notablemente en las últimas décadas por el desarrollo de nuevas infraestructuras de transporte.

Igualmente, cabe destacar las transformaciones operadas en los modelos familiares, propias de las sociedades avanzadas pero que llegaron al caso español algo más tarde (reducción del número de hijos, familias monoparentales, nuevos hogares resultado de divorcios, etcétera), y que en general se han traducido en una disminución en promedio del número de ocupantes de las viviendas y, por tanto, en la necesidad de un mayor número de estas (a título de ejemplo, entre 1991 y 2001 más del 55\% de los nuevos hogares creados fueron unipersonales [La Caixa, 2003]).

\section{Causas normativas e institucionales}

Este tema, centrado en la mayor o menor incidencia de las reformas aprobadas en la legislación del suelo, ha sido muy debatido por especialistas españoles en los últimos años (García Bellido, 2005; Leal, 2007; Parejo Alfonso, 2007); en concreto, la reforma se plasmó el año 1998 en la denominada Ley No 6/1998 sobre Régimen de Suelo y Valoraciones, la cual se ha mantenido en vigor hasta la nueva Ley del Suelo de 2007. En resumen, aquella norma, a partir del principio teórico de que una ma- 
yor oferta de suelo urbanizable a disposición de los agentes abarataría el precio final de la vivienda, introdujo un potente factor de liberalización del mercado de suelo al concebir como urbanizable toda aquella superficie que no estuviera específicamente protegida (aunque no sea la finalidad de este artículo, cabe decir que la elevación de los precios de la vivienda en España durante los años de vigencia de la ley parecen desmentir dicho principio).

Es una opinión extendida (Rodríguez López, 2007; Ocaña, 2009) que esta liberalización ha facilitado y, por ello, potenciado la extensión del proceso urbanizador en buena parte de la geografía española. Sin embargo, si bien entendemos que ello puede ser cierto en comunidades autónomas como Madrid, Murcia o Comunidad Valenciana, cuyas legislaciones regionales asumieron las orientaciones de la normativa estatal, es igualmente cierto que otras comunidades con gobierno de signo político diferente aprobaron legislaciones que contrarrestaban el sesgo liberalizador señalado, otorgando mayor peso a la capacidad planificadora de las administraciones públicas (uno de los casos más significativos sería el de Andalucía, con la Ley No 7/2002 de Ordenación Urbanística de Andalucía). Pues bien, si se analizan la realidad territorial resultante, el número de viviendas construidas o el comportamiento de los agentes implicados (véanse más adelante cuadros y mapas para el caso andaluz), no cabe sino señalar la dificultad de encontrar diferencias sustanciales entre comunidades con legislaciones urbanísticas de distinta inspiración. Esto confirmaría, si bien no es el tema central de esta investigación, la reducida capacidad real por parte de los poderes públicos españoles (al menos en lo que se refiere a la escala supramunicipal, siendo diferente en la escala local) para incidir decisivamente en los procesos territoriales cuando vienen impulsados por factores macroeconómicos como los ya señalados en este texto. A ello se añadiría la debilidad financiera estructural de los municipios españoles, que han encontrado en la instrumentación del urbanismo y la actividad constructora una fórmula para compensar dicha fragilidad, subordinando el objetivo de lograr un orden territorial racional a la necesidad de transformar el urbanismo en una herramienta de mantenimiento de las haciendas locales.

\section{Caracterización y diferenciación del caso andaluz en el contexto español. Síntesis estadística}

Este apartado se dirige a mostrar, a partir de una selección de datos estadísticos básicos, los principales rasgos caracterizadores del sector de la construcción en la Comunidad Autónoma de Andalucía y de su evolución en los últimos años, mostrando lo relevante del caso andaluz dentro del contexto español, debido a la magnitud alcanzada por el fenómeno aquí estudiado.

Como primera aproximación, si se analiza el peso del valor añadido bruto de los diferentes sectores productivos, destaca el sector servicios como el preponderante tanto a nivel andaluz como español. Sin embargo, en lo que se refiere a la construcción, desde el año 2002 este sector se ha convertido en el segundo en importancia de la región, lo que hace de Andalucía una singularidad, ya que, en el caso global español, durante todo el período 1995-2008 fue el sector industrial el que ocupó el 
segundo lugar en importancia, tras el sector servicios. En este sentido, destaca que el sector de la construcción haya experimentado un crecimiento en valores relativos superior al resto de los sectores durante la primera década del siglo, con un crecimiento acumulado en el año 2007 del 150\% respecto del año 2000.

A análogas conclusiones se puede llegar estudiando el fenómeno a partir de determinados indicadores relacionados con el subsector de la vivienda. Así, si se consideran las licencias municipales de obras concedidas en Andalucía, se obtiene que en el año 2006 se destinaron 28,49 millones de metros cuadrados de superficie para la construcción de viviendas libres de nueva planta. Andalucía destaca, así, como la comunidad autónoma española que más superficie destinó a tal fin —representa el 20\% del valor estatal—, y cuyo valor anual ha ido en ascenso hasta el año 2007 (Ministerio de Fomento, 2007).

Si se analiza la evolución del número de viviendas libres terminadas y las variaciones porcentuales interanuales del precio de las viviendas desde 1996 hasta 2008 (Figura 2), se obtiene que, partiendo de una producción de aproximadamente 30.000 viviendas libres en 1996, se registró para el año 2006 una producción cercana a las 124.000 viviendas, lo que da un total de producción de vivienda libre durante el período 1996-2006 de 1.109.264 unidades. A partir de dicho año se registran descensos, similares en magnitud a los que ya se observaron en los años 2003 y 2004, pero con la diferencia de que en esta ocasión la caída no parece deberse a una tendencia de ajuste puntual del mercado de la vivienda; se vincula, más bien, al proceso estructural de crisis económica y cambio de ciclo, motivo por el cual se constatarán bajadas más acusadas hasta el final de la década (como se comprueba en las cifras globales de España ofrecidas en un epígrafe anterior).

FIGURA 2 Perfil del último ciclo de la vivienda en Andalucía (1996-2010)

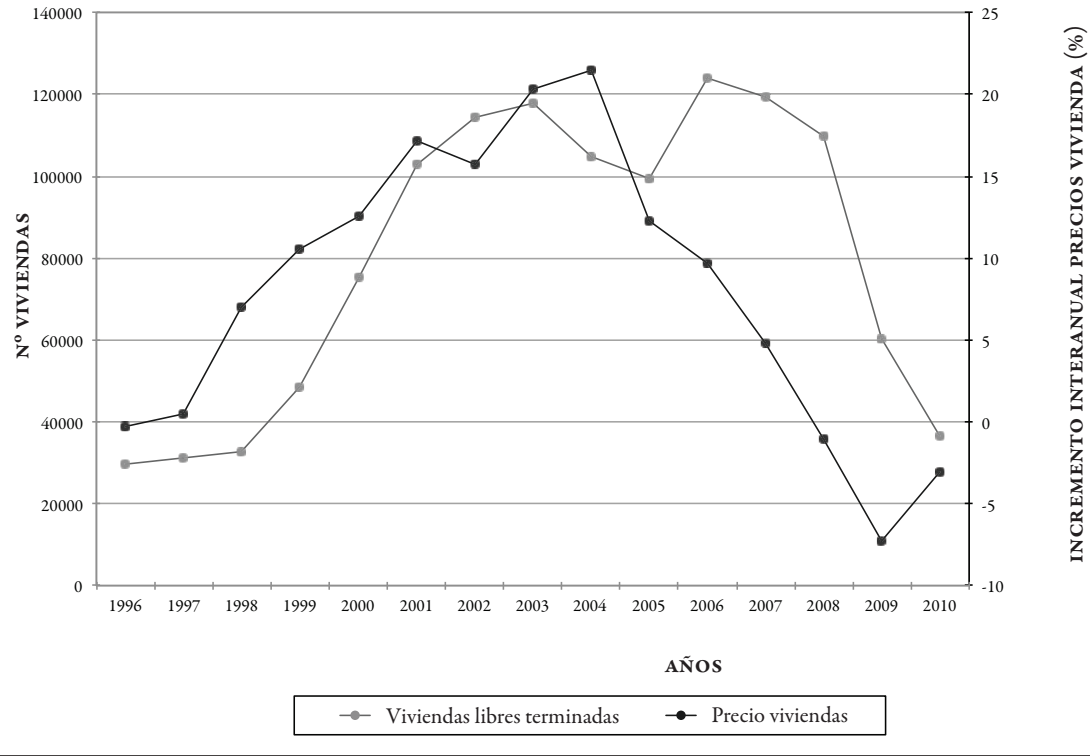

FUENTE ELABORACión PROPIA A PARTIR DE DATOS DEL MiNisterio DE ViVIENDA. 
Respecto del precio de la vivienda, en la figura se muestran las variaciones interanuales de los precios desde 1996 hasta 2008. Destaca el hecho de que en casi todo el periodo se registran variaciones positivas, no habiéndose producido un decrecimiento en dichos precios respecto del año anterior hasta 2008, como consecuencia de la paralización del mercado y la necesidad de dar salida al stock de viviendas acumulado. Esta situación es muy diferente a la que se alcanzó en 2004, momento en el que se dio un máximo de crecimiento interanual, superior al $20 \%$. Desde ese año, los precios, aunque siguieron subiendo, lo hicieron a un ritmo cada vez menor, hasta llegar a la citada variación negativa en 2008. Hay que decir que, con relación al resto de comunidades autónomas, Andalucía es la que ha registrado en los últimos años una bajada de precios menor en promedio (si bien sí se detectan descensos más apreciables en las zonas litorales mediterráneas), con la particularidad, además, de que los precios del suelo han seguido subiendo hasta dicho año 2008, a diferencia del promedio general español (Ministerio de la Vivienda, 2010).

\section{Análisis territorial de la actividad constructora y urbanizadora en Andalucía a escala comarcal. Fuentes, método y resultados}

En este apartado se propone una serie de indicadores que permiten cuantificar distintos aspectos de la temática tratada y se aplican los mismos al caso de Andalucía, distinguiéndose los diferentes comportamientos y dinámicas que se han dado en

el territorio regional, dentro del contexto general ya caracterizado; finalmente, se procede a cartografiar los resultados obtenidos, como paso previo a su interpretación y valoración (no obstante, hay que señalar que en el presente artículo, por razones de espacio, no se reproduce la totalidad de mapas y cuadros originalmente elaborados). Con ello se pretende avanzar en la explicación de los pormenores del fenómeno tratado, así como - en la medida de lo posible en un artículo de estas características - introducir un componente demostrativo aplicado a un caso territorial concreto, que contribuya a dar respuesta a las preguntas esenciales planteadas en la investigación.

\section{Fuentes de información y variables seleccionadas}

Las variables seleccionadas para su estudio y las fuentes utilizadas se detallan en el Cuadro 2. Estas variables pueden ser agrupadas en tres epígrafes —orientación municipal hacia la actividad inmobiliaria, dinámica del mercado de la vivienda y repercusiones de la intensidad de la actividad constructora-, que se corresponden con los distintos objetivos informativos que se ha pretendido cubrir.

\section{a) Orientación municipal hacia la actividad inmobiliaria}

Las variables seleccionadas en este acápite están dirigidas en conjunto a mostrar el peso proporcional alcanzado por la actividad inmobiliaria a escala municipal, tanto 
en lo económico como en lo social y territorial. Es preciso aclarar algunas cuestiones relativas a los indicadores seleccionados, como son:

- Impuesto de Bienes Inmuebles de Naturaleza Urbana. Base Imponible. Este impuesto se calcula a partir de una base imponible derivada de las características objetivas, tanto cuantitativas como cualitativas, del parque inmobiliario de cada municipio, a la cual se aplican cuotas o coeficientes multiplicadores establecidos según decisión de cada ayuntamiento. El indicador aquí comentado, al tomar solamente la base imponible, resultante de criterios homogéneos para todos los municipios, permite realizar una comparación intermunicipal del valor de los bienes inmuebles presentes en los mismos.

\section{CUADRO 2 Variables seleccionadas y fuentes}

\begin{tabular}{|c|c|}
\hline TÍTULO & FUENTE \\
\hline $\begin{array}{l}\text { Impuesto de Bienes Inmuebles (IBI) de Naturaleza } \\
\text { Urbana. Base Imponible (2006) }\end{array}$ & $\begin{array}{l}\text { Dirección General del Catastro. Ministerio de Economía } \\
\text { y Hacienda }\end{array}$ \\
\hline $\begin{array}{l}\text { Proporción IBI Urbana (Base Cuota) sobre el total del } \\
\text { presupuesto municipal (2006) }\end{array}$ & $\begin{array}{l}\text { Dirección General del Catastro. Ministerio de Economía } \\
\text { y Hacienda } \\
\text { Sistema de Información Multiterritorial de Andalucía } \\
\text { (SIMA), Instituto de Estadística de Andalucía (IEA) }\end{array}$ \\
\hline Índice de Función Residencial No Permanente (2008) & $\begin{array}{l}\text { Dirección General del Catastro. Ministerio de Economía } \\
\text { y Hacienda } \\
\text { Sistema de Información Multiterritorial de Andalucía } \\
\text { (SIMA), Instituto de Estadística de Andalucía (IEA) }\end{array}$ \\
\hline $\begin{array}{l}\text { Empleo en la construcción sobre el total del empleo en el } \\
\text { municipio (2006) }\end{array}$ & Seguridad Social \\
\hline $\begin{array}{l}\text { Evolución del número de empleados en la construcción } \\
(2000-2006)\end{array}$ & Seguridad Social \\
\hline Transacciones de vivienda 2006 & Ministerio de la Vivienda \\
\hline Variación de transacciones de vivienda 2006-2008 & $\begin{array}{l}\text { Sistema de Información Multiterritorial de Andalucía } \\
\text { (SIMA), Instituto de Estadística de Andalucía (IEA) }\end{array}$ \\
\hline $\begin{array}{l}\text { Proporción de transacciones sobre total de unidades } \\
\text { catastrales de uso residencial } 2008 .\end{array}$ & $\begin{array}{l}\text { Ministerio de la Vivienda } \\
\text { Dirección General del Catastro. Ministerio de Economía } \\
\text { y Hacienda }\end{array}$ \\
\hline Modificaciones puntuales del planeamiento 2000-2009 & $\begin{array}{l}\text { Consejería de Vivienda y Ordenación del Territorio. Junta } \\
\text { de Andalucía }\end{array}$ \\
\hline $\begin{array}{l}\text { Relación entre incidencia laboral del sector de la } \\
\text { construcción (2006) y evolución del desempleo posterior } \\
(2006-2008)\end{array}$ & $\begin{array}{l}\text { Seguridad Social } \\
\text { Sistema de Información Multiterritorial de Andalucía } \\
\text { (SIMA), Instituto de Estadística de Andalucía (IEA) }\end{array}$ \\
\hline
\end{tabular}

FUENTES ELABORACIÓN PROPIA.

- Proporción IBI Urbana (Base Cuota) sobre el total del presupuesto municipal. En este caso se toma el montante del IBI de Naturaleza Urbana con la denominada "Base Cuota", es decir, una vez que se han aplicado las cuotas diferenciales 
aprobadas por cada municipio, de lo que resulta el valor real del IBI recaudado. Este dato se pone en relación proporcional con el total del presupuesto del ayuntamiento para cada uno de los municipios andaluces, obteniéndose de esta forma un indicador de la trascendencia alcanzada por la fiscalización de la riqueza inmobiliaria en el conjunto de dichos presupuestos.

- Índice de Función Residencial No Permanente. Es resultado del cociente de las unidades catastrales de uso residencial de un municipio entre los habitantes de derecho del mismo. Al indicar la relación entre el volumen de viviendas y la población de derecho o permanente, muestra el peso proporcional alcanzado por las viviendas desocupadas o las de uso estacional (como segundas residencias de uso vacacional) (Vera, 2005). De esta forma, este indicador cubre las carencias de información derivadas de la periodicidad decenal de la principal fuente utilizada hasta ahora para analizar dicha cuestión, como es el Censo de Población y Vivienda.

- Empleo en la construcción sobre el total del empleo en el municipio, y evolución del número de empleados en la construcción entre 2000 y 2006. Con estos indicadores se amplía el análisis al conjunto del sector de la construcción, superando el ámbito de lo estrictamente inmobiliario. Dichos empleos se contabilizan a partir de los registros de afiliados en la Seguridad Social.

\section{b) Dinámica del mercado de la vivienda}

Los indicadores utilizados se orientan a mostrar la situación y evolución del mercado de viviendas a escala municipal, debido a la trascendencia de dicho mercado como principal motor del sector de la construcción, y por la importancia alcanzada por sus fluctuaciones como factor explicativo de la evolución del entorno socioeconómico en varios municipios andaluces.

Los tres indicadores utilizados (Transacciones de vivienda por municipio en 2006; Variación de dichas transacciones entre 2006 y 2008; y Proporción de transacciones sobre total de unidades catastrales de uso residencial en 2008) se refieren a la compraventa de viviendas, tanto nuevas como usadas, relacionándolas en el tercer caso con las unidades catastrales de uso residencial de cada municipio, para hacer el indicador proporcional al tamaño de su parque inmobiliario.

\section{c) Repercusiones de la intensidad de la actividad constructora}

Dirigidos a mostrar las consecuencias diferenciadas que han experimentado los distintos territorios en función de su mayor o menor orientación hacia la actividad inmobiliaria y constructiva en general, los indicadores seleccionados han sido:

- Modificaciones puntuales del planeamiento entre 2000 y 2009. Se emplea esta variable al considerar que la práctica de aprobar modificaciones no previstas en el planeamiento urbanístico vigente refleja la intensidad y aceleración de la dinámica urbanizadora y constructora en los municipios, de forma que quedan desbordadas las previsiones iniciales; igualmente, la frecuencia de estas modi- 
ficaciones revela deficiencias en la calidad de la acción planificadora, si bien no es esta una temática que se trate en este artículo.

- Relación entre incidencia laboral del sector de la construcción (2006) y evolución del desempleo posterior (2006-2008). La aplicación de este indicador da como resultado el establecimiento de una tipología de municipios según su comportamiento al respecto, poniendo en relación el porcentaje de empleos en la construcción sobre el total de empleos del municipio, con el posterior incremento o descenso del desempleo global en el mismo. Con ello se intenta mostrar el nivel de vulnerabilidad en sus estructuras socioeconómicas experimentado por aquellas áreas que han mostrado mayor dependencia hacia la actividad constructora. En concreto, se ofrece una tipología de comarcas con seis categorías, resultado de combinar dos variables:

- Proporción del empleo en la construcción sobre total de empleos, en 2006. Se distingue entre municipios con marcada dependencia del sector (por encima del promedio regional, cifrado en 15\%) o reducida dependencia (por debajo del 15\%).

- Incidencia del incremento del desempleo entre 2006 y 2008. Se distingue entre municipios con incidencia moderada (crecimiento del desempleo por debajo del 20\%); incidencia intensa (incremento entre el 20\% y el 50\%); e incidencia muy intensa (crecimientos superiores al 50\% en el periodo).

\section{Escalas de tratamiento de los datos y agregación territorial de los resultados}

Los indicadores anteriormente presentados han sido calculados a escala municipal (en Andalucía existen 770 municipios). No obstante, para apreciar y valorar mejor algunos procesos y tendencias, resulta conveniente la consideración de lecturas territoriales de enfoque más amplio o menor singularización en casos puntuales municipales; es por ello que aquí se ofrecen dichas lecturas territoriales, basadas en la agrupación de municipios. Estas agrupaciones se sustentarán en criterios tales como:

- La agregación comarcal de municipios. Para ello se utilizará la base comarcal asentada en los estudios del Informe de Desarrollo Territorial de Andalucía, en sus ediciones primera y segunda (Zoido, 2001; Zoido \& Caravaca, 2005). Esta base comarcal se representa en la Figura 3. Se ofrecen los mapas comarcales correspondientes a cada una de las variables (excepto en los casos de "IBI de Naturaleza Urbana. Base Imponible" y "Modificaciones puntuales de planeamiento", al considerar que presentaban escasa significación en su agregación comarcal).

- La agrupación de los datos comarcales por grandes unidades territoriales. El propósito es extraer conclusiones acerca del comportamiento de las variables en función de una lectura territorial, basada en los grandes conjuntos espaciales que otorgan carácter diferenciado a sus territorios o comarcas componentes. En concreto, se han distinguido cuatro grandes unidades territoriales. Al 
agruparse los datos comarcales en función de las mismas, estas unidades son:

- Litoral.

- Aglomeraciones urbanas.

- Áreas agrícolas interiores.

- Áreas serranas.

- La agrupación de los municipios según su tamaño poblacional. El objetivo es deducir pautas de comportamiento diferenciadas no tanto por la localización de los municipios, sino por su dimensión (poblacional, en este caso). Para este fin se va a considerar la siguiente clasificación de volúmenes poblacionales, que simplifica la establecida por el Instituto Nacional de Estadística.

- Municipios con población hasta 2.000 habitantes.

- De 2.001 a 10.000 habitantes.

- De 10.001 a 50.000 habitantes.

- De 50.001 a 100.000 habitantes.

- De 100.001 a 500.000 habitantes.

- Más de 500.000 habitantes.

FIGURA 3 Base comarcal

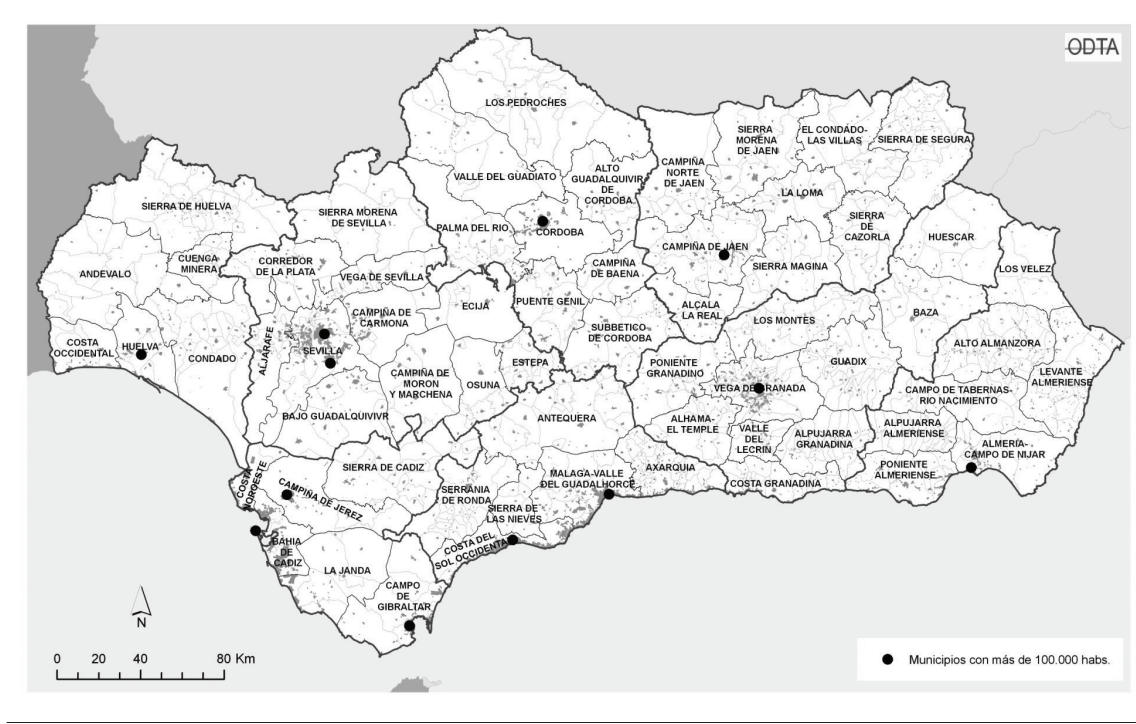

fuente Informe de Desarrollo Territorial de Andalucía.

Resultados: Distribución territorial de los indicadores en Andalucía y valoración de la misma

Este epígrafe, orientado a diferenciar el comportamiento con relación a la actividad constructora de las diferentes subunidades del territorio andaluz, se estructura en tres apartados correspondientes a los objetivos señalados con anterioridad: orienta- 
ción municipal hacia la actividad inmobiliaria, dinámica del mercado de la vivienda y repercusiones de la intensidad de la actividad constructora.

\section{a) Orientación municipal hacia la actividad inmobiliaria}

El primer indicador considerado es el total de lo recaudado por el Impuesto de Bienes Inmuebles de Naturaleza Urbana para cada municipio en 2006. Esta primera aproximación permite apreciar la distribución del valor fiscal del parque inmobiliario en el territorio, lógicamente muy dependiente del tamaño poblacional, aunque matizado por las diferencias en el valor de los inmuebles. Consecuentemente, destaca la fuerte presencia de las grandes aglomeraciones urbanas (Sevilla y Málaga, sobre todo), con una apreciable desviación positiva en las áreas litorales más dinámicas, debido al elevado valor promedio alcanzado por sus parques inmobiliarios, tales como la Costa del Sol Occidental, el Poniente Almeriense o la Bahía de Cádiz.

Mayor precisión desde el punto de vista cualitativo ofrece el siguiente indicador, la proporción porcentual que significa la recaudación del IBI de Naturaleza Urbana sobre el montante total del presupuesto municipal (mapa comarcal en Figura 4). Este aspecto reviste notable importancia, debido a que revela el grado de dependencia que las haciendas locales presentan respecto de la tributación derivada de su parque inmobiliario, factor este que no puede ser ignorado a la hora de explicar la oleada de expansión urbanizadora que ha recorrido Andalucía y España en los últimos años. El mapa revela cómo, salvo alguna excepción en el interior rural, son las coronas metropolitanas de las grandes aglomeraciones y las áreas con mayor presencia de urbanizaciones turístico-residenciales (ya sea en el litoral: Costa del Sol Occidental, Bahía de Cádiz, Costa Noroeste de Cádiz; o en algunas áreas de montaña: estación de esquí de Sierra Nevada) las que presentan valores más elevados, demostrándose así su coincidencia con las áreas en las que más intenso ha sido el crecimiento urbanístico desde comienzos de la década.

Estas pautas se corresponden con los valores promedio por grandes unidades territoriales, entre los que destaca la muy elevada cifra alcanzada por el conjunto de áreas litorales (17,51\% del presupuesto municipal) y urbanas (14,16\%), que las coloca en una situación de marcada dependencia respecto de esta fuente de financiación. En ese aspecto están a una amplia distancia de las áreas serranas (9,44\%) y agrícolas interiores $(8,82 \%)$, si bien los promedios alcanzados por estas, siempre cercanos al $10 \%$, no pueden ser calificados de reducidos, debido a los elevados valores globales que muestra el conjunto regional.

Como última corroboración, se aporta el Cuadro 3, en el que se distingue una clara correlación positiva entre la dimensión poblacional del municipio y su nivel de dependencia presupuestaria respecto de los ingresos derivados del IBI, en correspondencia con la mayor concentración de población y actividad urbanizadora en el litoral y grandes aglomeraciones urbanas, frente al predominio de núcleos pequeños en las áreas interiores. 
FIGURA 4 Proporción IBI urbana (Base Cuota) sobre el total del presupuesto municipal. Base comarcal

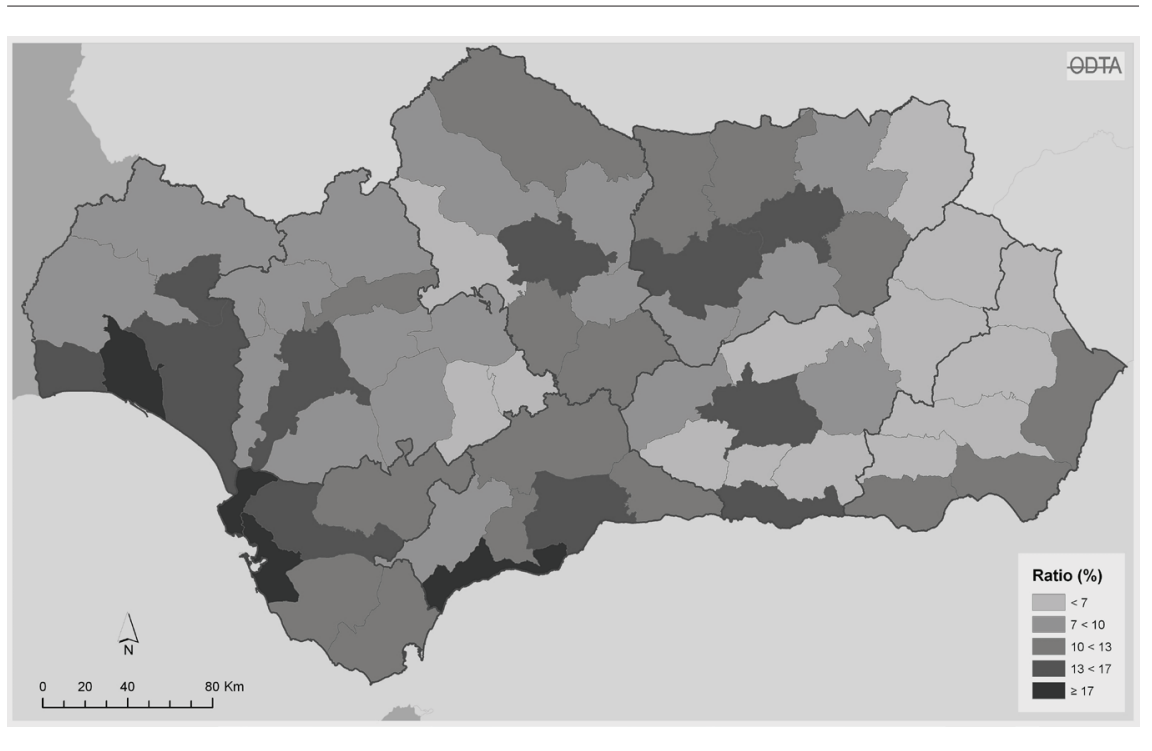

Fuente elaboración propia a partir de Dirección General del Catastro. Ministerio de Economía y

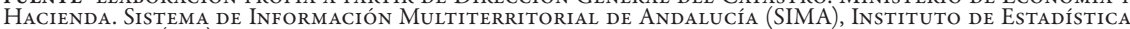
DE ANDAlucía (IEA).

CUADRo 3 Proporción IBI urbana (Base Cuota) sobre el total del presupuesto municipal (2006). Por intervalos de población del municipio

\begin{tabular}{lc}
\hline INTERVALOS DE POBLACIÓN & \% IBI URBANA / PRESUPUESTO MUNICIPAL \\
\hline$<2.000$ & 5,32 \\
$2.001<10.000$ & 9,60 \\
$10.001<20.000$ & 10,82 \\
$20.001<50.000$ & 13,35 \\
$50.001<100.000$ & 16,02 \\
$100.001<500.000$ & 16,65 \\
$>500.001$ & 14,08 \\
\hline
\end{tabular}

fuente elaboración propia a partir de Dirección General del Catastro. Ministerio de Economía y Hacienda. Sistema de Información Multiterritorial de Andalucía (SIMA), Instituto de Estadística De Andalucía (IEA).

En cuanto al Índice de Función Residencial No Permanente (mapa comarcal en Figura 5), se muestra una marcada intensidad en el número de unidades catastrales de uso residencial por habitantes de derecho (o, en términos equivalentes, en el 
volumen proporcional del parque de viviendas destinadas a usos estacionales) en aquellas áreas con notable presencia de atractivos desde el punto de vista del turismo y el ocio. Entre ellas, las áreas litorales con penetración hacia el interior para rentabilizar la comodidad climática, así como las áreas serranas con elevada calidad ambiental; espacios estos — en conjunto - en los que se han extendido de manera masiva las residencias secundarias de uso vacacional (si bien cabe señalar que, en algunas áreas serranas, la presencia destacable de viviendas vacías o desocupadas, resultado del éxodo rural, puede dificultar la interpretación de los resultados). En concreto, destacan con los valores más elevados la Costa del Sol, tanto Occidental como Oriental (el municipio de Benahavís alcanza el máximo valor de Andalucía, con 1,58 viviendas por cada habitante de derecho), la Costa Tropical Granadina, el Levante Almeriense y la Costa de Huelva, entre las litorales; y los parques naturales de Sierra Nevada, Sierra de Aracena y Picos de Aroche, Cazorla-Segura-Las Villas, y Sierra de Grazalema, entre otros. Todo ello en contraste con las áreas agrícolas y aglomeraciones urbanas del interior, cuyas condiciones naturales y paisajísticas, así como los modelos de ocio asociados a las mismas, propician un reducido número de viviendas vacacionales.

FIGURA 5 Índice de función residencial no permanente, 2008. Base comarcal

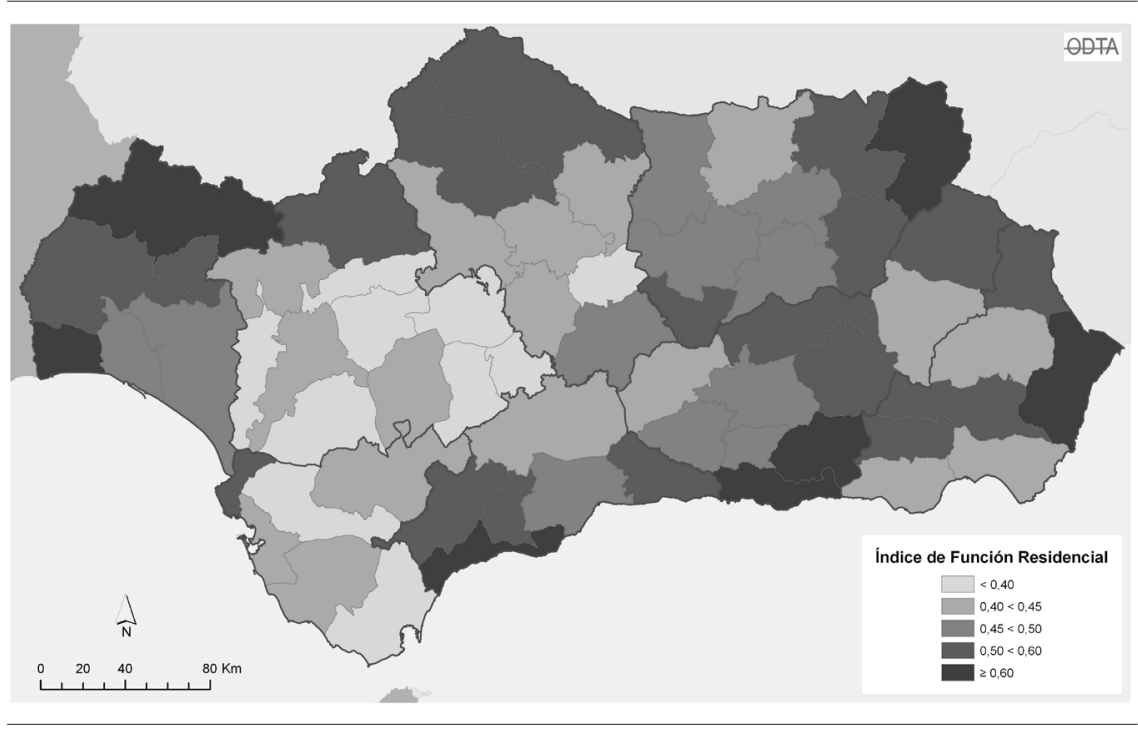

fuente elaboración propia a partir de Dirección General del Catastro. Ministerio de Economía y Hacienda. Sistema de Información Multiterritorial de Andalucía (SIMA), Instituto de Estadística de Andalucía (IEA).

Estas diferenciaciones se constatan en el resumen de valores por grandes unidades territoriales, en el que los resultados de las áreas litorales $(0,59)$ se distinguen nítidamente del resto de áreas, con similares datos para áreas urbanas $(0,43)$ y rura- 
les $(0,42)$ (en principio poco propicias a las residencias secundarias por motivos de ocio) y una leve alza en lo relativo a las serranas $(0,48)$.

Por el contrario, no se observan patrones muy definidos en la clasificación de valores por tamaño municipal, al combinarse en los mismos intervalos núcleos de áreas litorales y urbanas, con comportamientos opuestos en este indicador. Solamente destacan los altos valores alcanzados por los municipios muy pequeños (menos de 2.000 habitantes), ya que suelen localizarse en ámbitos de sierra con un parque inmobiliario de escaso volumen, por lo que la presencia de un cierto número de residencias secundarias o viviendas desocupadas - no necesariamente muy elevado - puede aumentar de forma muy notable el resultado final.

En lo que respecta a los indicadores basados en el empleo, esenciales para la explicación de las repercusiones sociales del fenómeno en estudio, se aporta en primer lugar el peso del empleo en el sector de la construcción sobre el total del empleo en el municipio en 2006 (mapa comarcal en Figura 6). En lo referente a este, hay que destacar el elevado promedio alcanzado para el total andaluz, cercano al 15\% del total de empleos, en clara muestra de la marcada orientación hacia la construcción alcanzada por la estructura socioproductiva andaluza. A escala local, casi trescientos municipios presentan más del $20 \%$ de empleo en el sector de la construcción, y hasta ocho municipios de más de 10.000 habitantes superan el 30\%. Los valores más elevados se localizan en una segunda línea de litoral cercana a las áreas turísticas más tradicionales, así como en la corona metropolitana externa de las grandes aglomeraciones y en áreas serranas con significativo crecimiento residencial-turístico.

FIGURA 6 Empleo en la construcción sobre el total del empleo en el municipio, 2006. Base comarcal

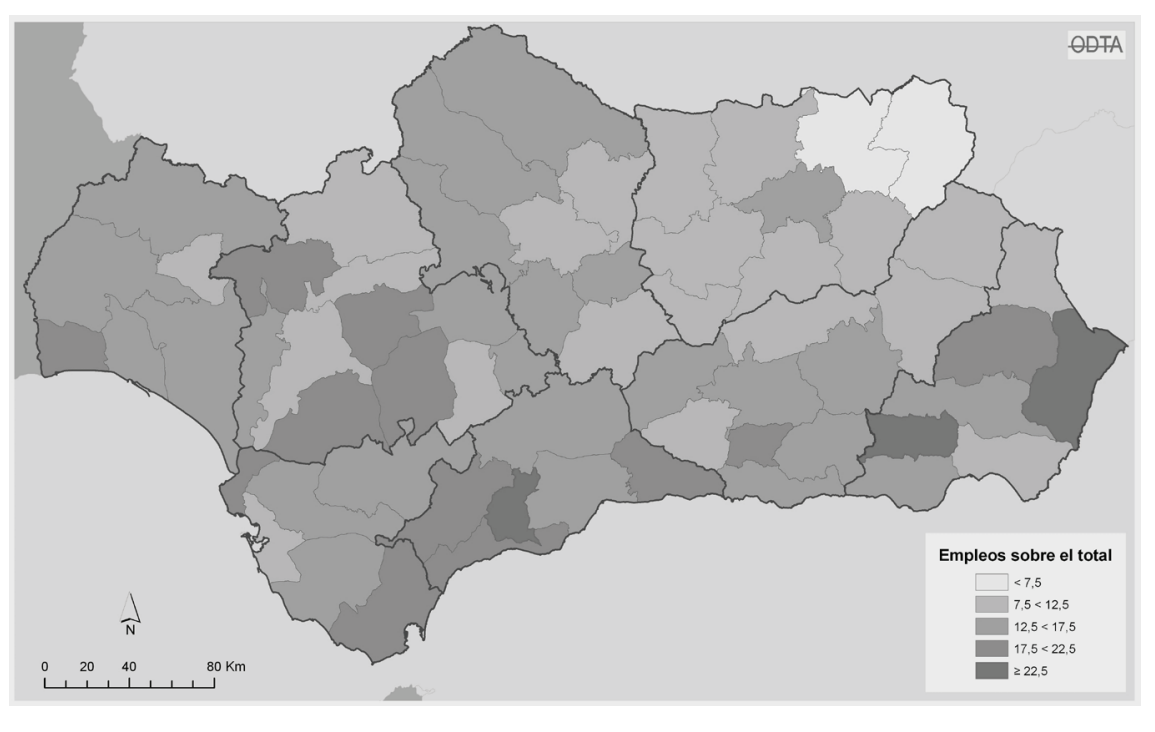

Fuente elaboración propia a partir del Registro de la Seguridad Social. 
De esta forma, el mapa citado muestra cómo las áreas con mayores valores, con más del 22,5\% del total de empleos radicado en la construcción, se ubican en la Alpujarra Almeriense, la Sierra de las Nieves malagueña, y el Levante Almeriense y su prolongación al interior. Ello se explica por el hecho de ser espacios inscritos o cercanos a áreas litorales de potente desarrollo residencial-turístico (hacia las que los trabajadores pueden dirigirse en desplazamientos de base diaria), a lo cual se suma que se trata de ámbitos con cierto desarrollo del residencialismo en los últimos años, como resultado de sus propios valores naturales y paisajísticos.

Junto con lo anterior, destacan en el mapa las elevadas cifras alcanzadas por buena parte de las comarcas andaluzas, siendo escasas las agrupables en los intervalos inferiores. Ello se ve confirmado por los datos acumulados por grandes unidades territoriales, en los que, junto al esperable primer lugar ocupado por las áreas litorales (18\%), destaca el segundo puesto alcanzado por las áreas agrícolas interiores. Con $15 \%$ del total de empleos, estas superan a las urbanas y serranas (ambas con 12\%), en clara demostración de hasta qué punto la basculación del mercado laboral hacia el sector de la construcción ha sido un fenómeno ampliamente extendido entre los diferentes espacios geográficos andaluces, con relativa independencia de la estructura productiva preexistente.

La anterior conclusión se refuerza en el análisis de los datos por tamaño del municipio, el cual ofrece como resultado la generalización de los elevados valores registrados, que abarcan la casi totalidad de intervalos (sólo Sevilla y Málaga se colocan por debajo del 10\% de los empleos entre los municipios de más de 500.000 habitantes). Los valores máximos se encuentran en las categorías intermedias (municipios entre 10.000 y 100.000 , con cifras cercanas o superiores al 17\%), pero con datos que incluso en los municipios más pequeños se aproximan al 15\%, en una nueva demostración de la ya citada basculación del mercado laboral.

Estos datos se completan, desde un enfoque cronológico, con el indicador de Evolución del número de empleados en la construcción entre 2000 y 2006 (mapa de la Figura 7). A este respecto, el crecimiento ha sido de tal magnitud que en casi la mitad de los municipios andaluces (375 municipios, que en conjunto albergan el 27\% de la población), el incremento ha superado la duplicación, con un reparto territorial muy diseminado, si bien destacan por sus valores los ámbitos inscritos o cercanos a las mayores aglomeraciones urbanas, donde lógicamente el crecimiento cuantitativo de la construcción ha sido más intenso. Tales serían los casos de la Vega de Sevilla y el Corredor de la Plata, en la provincia de Sevilla, y el Poniente Granadino y la comarca de Los Montes, en la provincia de Granada, junto a la Alpujarra Almeriense, que alcanzan los valores más elevados como consecuencia de sus reducidos niveles de partida en el año 2000. Esta idea se confirma en la agrupación por grandes unidades territoriales, en la que se constata cómo es precisamente en las áreas agrícolas interiores donde mayores ritmos de crecimiento se han registrado $(218$, tomando como base 100 los datos del año 2000), debido al reducido nivel de base ya señalado. De nuevo, sin embargo, llaman poderosamente la atención los intensos crecimientos experimentados por la totalidad de áreas (serranas: 179; litorales: 167; urbanas: 160). 
FIGURA 7 Evolución de empleados en la construcción 2000-2006. Base comarcal

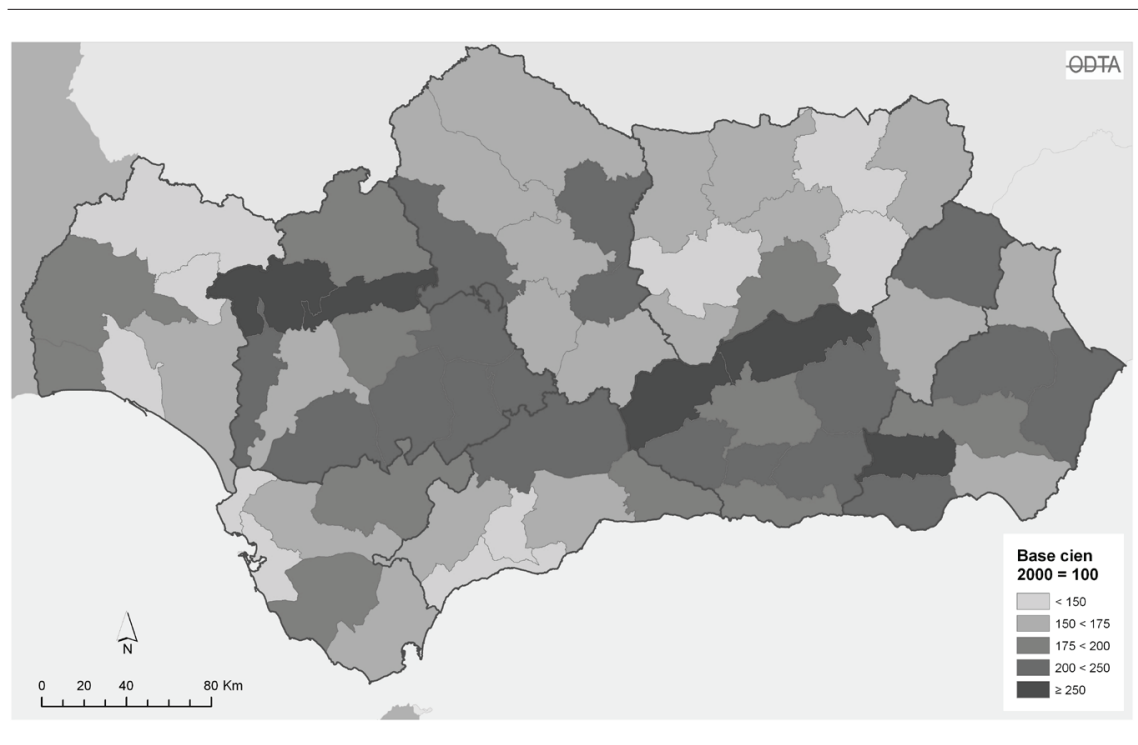

Fuente elaboración propia a partir del Registro de la Seguridad Social.

En efecto, el Cuadro 4, por tamaños de población, muestra una clara relación inversa entre dimensión del municipio e incremento proporcional del número de empleados en el periodo, evidenciando que han sido los municipios pequeños de ámbitos rurales y serranos, con escasa actividad constructora antes de la presente década, los que se han incorporado con un ritmo más intenso - proporcionalmente a su población - a la oleada inmobiliaria que ha recorrido Andalucía.

CUADRO 4 Evolución del número de empleados en la construcción (2000 - 2006). Por intervalos de población del municipio

\begin{tabular}{l|c}
\hline INTERVALOS DE POBLACIÓN & EVOLUCIÓN EMPLEADOS (2000 BASE CIEN) \\
\hline$<2.000$ & 216,36 \\
$2.001<10.000$ & 205,61 \\
$10.001<20.000$ & 206,87 \\
$20.001<50.000$ & 174,00 \\
$50.001<100.000$ & 173,76 \\
$100.001<500.000$ & 143,14 \\
$>500.001$ & 146,29 \\
\hline
\end{tabular}

FUENTE ELABORACIÓN PROPIA A PARTIR DE SEGURIDAD SOCIAL. 


\section{b) Dinámica del mercado de la vivienda}

El primero de los tres indicadores seleccionados, Transacciones de viviendas en 2006 (mapa de la Figura 8), muestra el elevado dinamismo alcanzado por dicho mercado en las aglomeraciones urbanas y áreas litorales. Se trata de un comportamiento estrechamente vinculado a la tendencia registrada hacia la consideración de la vivienda como un bien de inversión (cuando no de especulación) antes que un bien de consumo, con el resultado de sucesivas compraventas de los bienes inmuebles con alzas progresivas en los precios. De esta forma, se aprecia con claridad el peso diferenciado de las grandes capitales y su entorno (Sevilla y Málaga), así como ámbitos litorales con intensa urbanización (como la Costa del Sol Occidental). Ello se evidencia igualmente en el análisis por grandes unidades territoriales, que ofrece en las grandes aglomeraciones urbanas tantas transacciones de vivienda (84.353) como en la suma de los otros tres conjuntos territoriales (si bien hay que recordar que en la categoría de aglomeraciones urbanas se integran ámbitos que igualmente presentan carácter litoral, tales como Málaga, Bahía de Cádiz, Campo de Gibraltar, Huelva o Almería). Consecuentemente, si se consideran los datos con relación a la población de los municipios, aparecerá la lógica correlación positiva esperable entre volumen de población y número de transacciones.

\section{FIGURA 8 Transacciones de vivienda, 2006. Base comarcal}

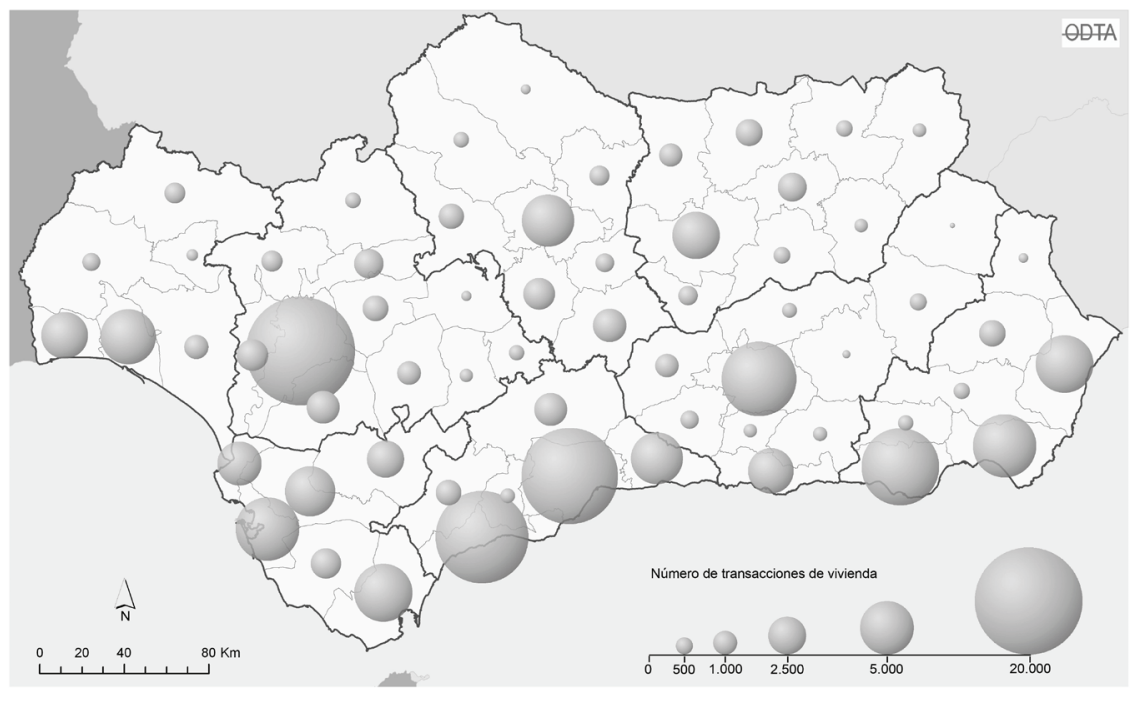

FUENTE ELABORACIÓN PROPIA A PARTIR DEL MiNisterio de LA VIVIENDA. 
El punto de inflexión de esta dinámica se produce a partir del estallido de la crisis económica, de forma que - como se muestra en el segundo indicador de este epígrafe "Variación de las transacciones de viviendas entre 2006 y 2008" (mapa de la Figura 9) - en dicho periodo se produce una caída muy extendida de las transacciones, destacando que a lo largo del litoral andaluz son excepcionales los municipios en los que haya aumentado el número de las mismas. De hecho, son muy escasas las áreas en las que crece el número de transacciones tras el año de máximos que significó 2006. Además, suelen ser espacios de escasa significación numérica en términos absolutos frente a una marcada caída en las áreas litorales, en especial las orientales, donde anteriormente la expansión fue mayor. Igualmente, el análisis por grandes unidades territoriales evidencia que son las áreas serranas (88) y agrícolas interiores (84), con menor dinamismo en el periodo previo, las que alcanzan valores más altos -o menos bajos, cabría decir - frente a unos ámbitos litorales que marcan los mínimos andaluces con unos valores promedios de 60, y aglomeraciones urbanas con 67, considerando los datos de 2006 como base 100; y ello en un contexto general en el que ninguno de los grandes conjuntos territoriales alcanza a igualar dicha base.

En consonancia con lo anterior, el Cuadro 5 muestra cómo en buena medida son los municipios de menor población los que proporcionalmente registran mejores comportamientos, en especial en el rango entre 2.000 y 10.000 habitantes, frente a la caída de las áreas más pobladas.

FIGURA 9 Variación de transacciones de vivienda, 2006-2008. Base comarcal

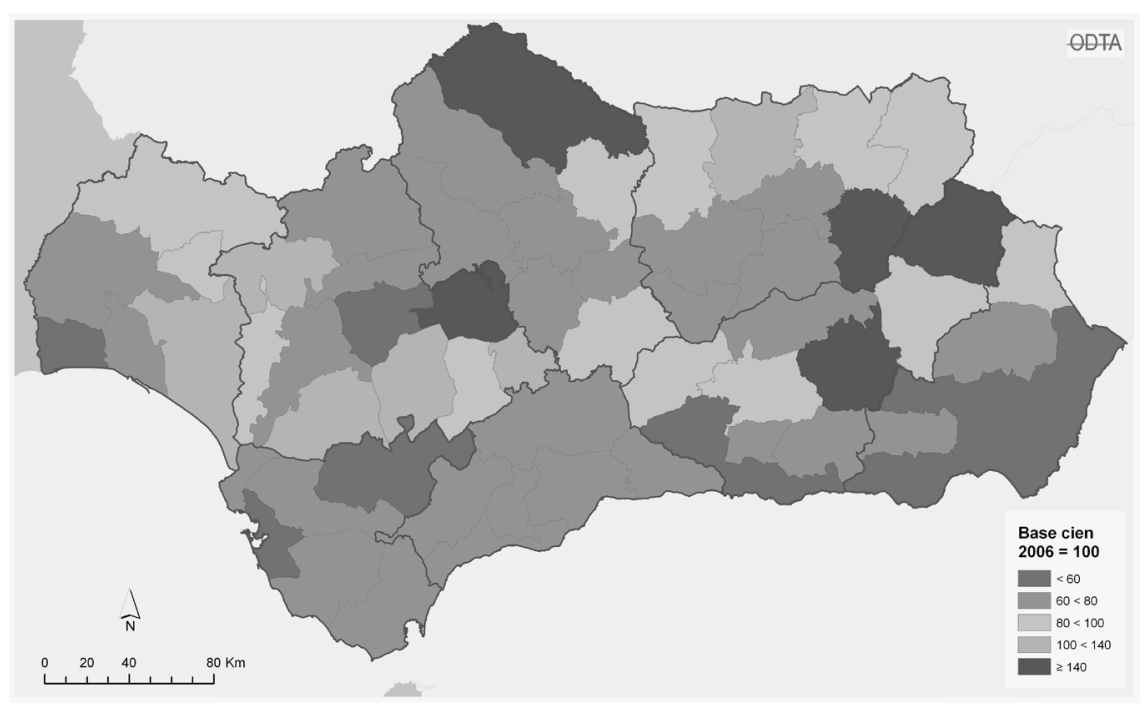

FUeNTE ELABoración PRopia a partir del Ministerio de la Vivienda. 
CUADRO 5 Variación de transacciones de vivienda 2006 - 2008. Por intervalos de población del municipio

\begin{tabular}{l|c}
\hline INTERVALOS DE POBLACIÓN & $\begin{array}{l}\text { EVOLUCIÓN TRANSACCIONES } \\
(2006 \text { BASE CIEN })\end{array}$ \\
\hline 2.000 & 72,07 \\
$10.001<20.000$ & 83,38 \\
$20.001<50.000$ & 69,35 \\
$50.001<100.000$ & 74,76 \\
$100.001<500.000$ & 62,74 \\
$>500.001$ & 60,33 \\
\hline
\end{tabular}

Fuente elaboración propia a partir de Sistema de Información Multiterritorial de Andalucía (SIMA), INSTITUTO DE EsTAdística DE ANDAlucía (IEA).

Las anteriores conclusiones se confirman con el tercer indicador de este bloque, "Proporción de las transacciones de vivienda sobre total de unidades catastrales de uso residencial en 2008" (mapa de la Figura 10), en el que se constata a niveles proporcionales cómo las áreas anteriormente más dinámicas no han recuperado dicha primacía, ocupada ahora por otras con menor parque inmobiliario, en las que inciden más poderosamente factores o iniciativas puntuales. Así, destacan ámbitos como el Corredor de la Plata, Bajo Guadalquivir, Alto Almanzora o Aljarafe (en su parte menos próxima a la capital sevillana), si bien no desaparecen totalmente de los primeros intervalos áreas litorales, representadas por el Poniente y el Levante almerienses. Ello muestra, así, la dificultad de extraer pautas territoriales nítidas, debido a la notable incidencia de factores locales que pueden modificar los resultados en un año como el considerado.

La dificultad mencionada en cuanto a la extracción de pautas territoriales claras se traduce igualmente en el análisis por grandes unidades territoriales y por tamaño poblacional, dominadas por una notable heterogeneidad de resultados territoriales, de la que solo emerge como conclusión la fortaleza, pese a todo, de las áreas litorales (en las que predominan núcleos medios de 10.000 a 100.000 habitantes). Dichas áreas siguen promediando los valores más elevados de Andalucía, si bien los puestos de primacía pasan de ámbitos más tradicionales, como la Bahía de Cádiz, a otros que parecen resistir mejor las nuevas condiciones adversas, como los ya señalados de la costa almeriense. 
FIGURA 10 Proporción de transacciones de vivienda sobre total de unidades catastrales de uso residencial, 2008

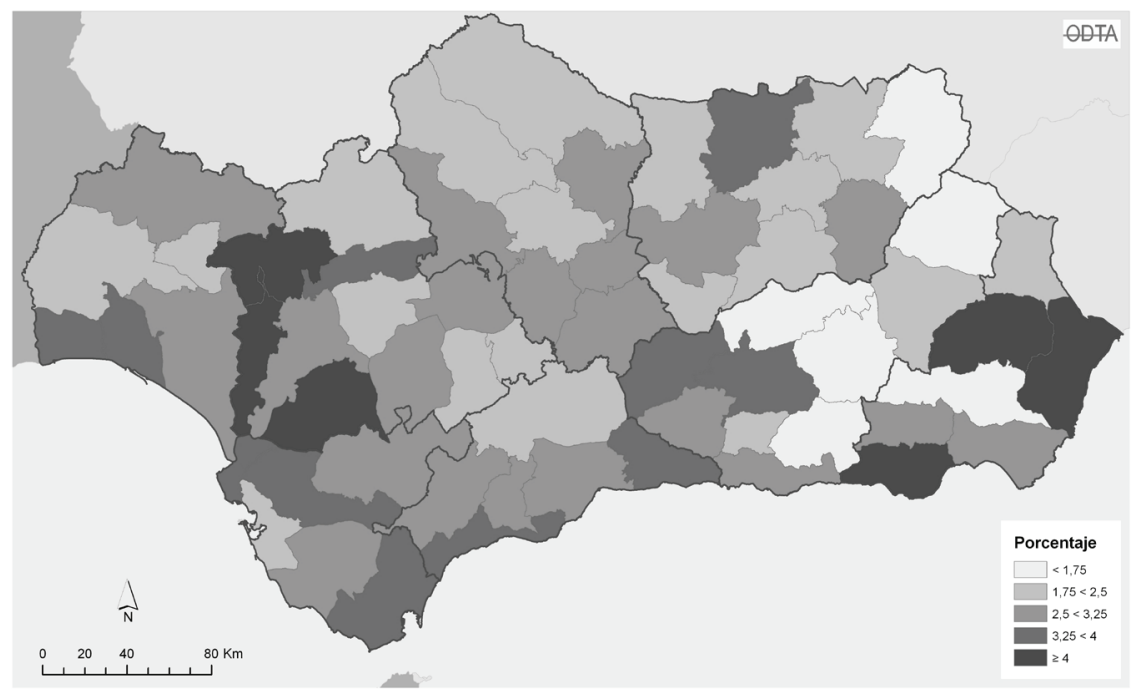

fuente elaboración propia a partir del Ministerio de la Vivienda, Dirección General del Catastro, Ministerio DE ECONOMÍA Y HACIENDA.

\section{c) Repercusiones de la intensidad de la actividad inmobiliaria}

En lo referente a las modificaciones puntuales de planeamiento entre 2000 y 2009 , se demuestra la relación entre el dinamismo del sector de la construcción y la proliferación de este tipo de actuaciones, al coincidir el mayor número de modificaciones con las áreas que los anteriores indicadores han mostrado como las de mayor intensidad constructora. Así, resaltan de nuevo la Costa del Sol, tanto Oriental como Occidental, aglomeraciones urbanas de Sevilla y Granada, Costa de Almería, Costa Occidental de Huelva o Bahía de Cádiz-Jerez.

Por lo que se refiere a la relación entre la incidencia laboral de la construcción (2006) y la evolución del desempleo a partir del estallido de la crisis (2006-2008), el mapa de la Figura 11 revela un acusado impacto del desempleo en las áreas que con mayor intensidad habían orientado sus estructuras socioproductivas hacia la construcción, frente a un comportamiento en general menos desfavorable en aquellas otras que presentaban una mayor diversificación en su economía productiva. Ello resulta de gran trascendencia, en tanto permite establecer una relación causal directa entre el dinamismo alcanzado por el sector de la construcción en algunas zonas, que en los casos más extremos puede calificarse de dependencia, y la vulnerabilidad o fragilidad de dichas zonas ante la aparición de la crisis económica tras 2006, traducida en un colapso de dicho sector que ha arrastrado a buena parte del tejido económico local, como lo demuestran los datos de desempleo. De esta forma, se aprecia la marcada correlación existente en la Costa del Sol Occidental y 
el Levante Almeriense entre orientación a la construcción e incidencia del desempleo, así como en las zonas de influencia de estas (sierras prelitorales, espacios de segunda línea de litoral), al extenderse a las mismas la expansión de urbanizaciones turístico-residenciales y, además, proveer de mano de obra a las actividades constructivas en los municipios propiamente costeros. También destacan, como ya se ha manifestado en otros indicadores, algunos espacios serranos de atractivo natural y las coronas metropolitanas.

Asimismo, se muestra que son muy escasas las comarcas en las que se dan las dos situaciones extremas opuestas a la correlación: escasa orientación a la construcción junto con muy intensa incidencia del desempleo (únicamente en Poniente Almeriense); o marcada orientación a la construcción que coincida con moderada incidencia del desempleo (solo en Campiñas de Morón y Marchena, Guadix y comarca de La Loma en la provincia de Jaén). La escasa proporcionalidad de estas áreas que parecen escapar a la correlación se manifiesta en el Cuadro 6, en el que se contabiliza el montante de población recogida en cada una de las seis categorías, y donde puede apreciarse el reducido volumen de habitantes comprendidos en los tipos extremos (232.027 en el primero de los citados y 215.778 en el segundo).

Por el contrario, tanto el mapa como el cuadro muestran la extensión territorial y volumen poblacional de los ámbitos en los que la correlación se cumple, siendo especialmente relevante la observación de aquellos en los que coincide una marcada orientación al sector de la construcción anterior al estallido de la crisis, con un muy intenso impacto del crecimiento del desempleo con posterioridad al mismo (Costa del Sol Occidental, Costa Granadina, Levante Almeriense y Alto Almanzora), junto a la lógica extensión de las situaciones intermedias.

FIGURA 11 Relación entre incidencia laboral del sector de la construcción (2006) y evolución del desempleo posterior, 2006-2008. Base comarcal

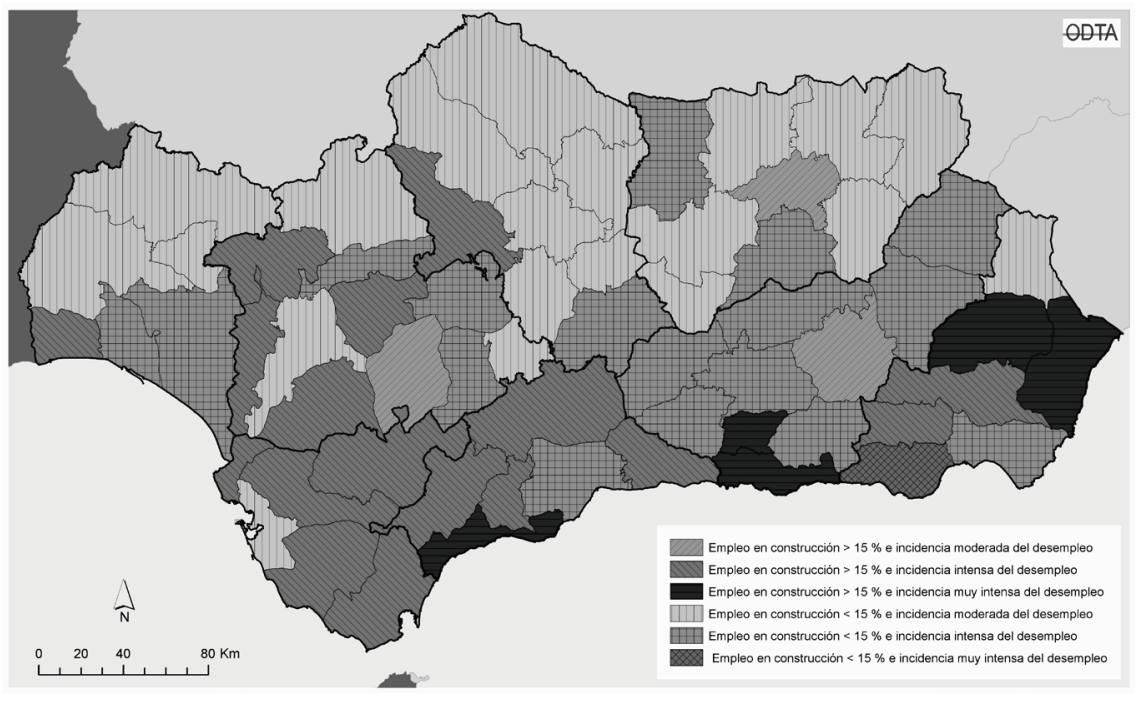

FUente elaboración propia a partir de la Seguridad Social y Sistema de Información MultiterritoRial De ANDAlucía (SIMA), InSTITUTO De Estadística De ANDAlucía (IEA). 
CUADRO 6 Población contenida en cada categoría de comarca según la relación entre incidencia laboral del sector de la construcción y evolución del desempleo posterior

\begin{tabular}{l|c}
\hline TIPO & POBLACIÓN 2008 \\
\hline Empleo en construcción $>15 \%$ e incidencia moderada del desempleo & 215.778 \\
Empleo en construcción $>15 \%$ e incidencia intensa del desempleo & 1.671 .705 \\
Empleo en construcción $>15 \%$ e incidencia muy intensa del desempleo & 649.783 \\
Empleo en construcción $<15 \%$ e incidencia moderada del desempleo & 2.891 .168 \\
Empleo en construcción $<15 \%$ e incidencia intensa del desempleo & 2.541 .759 \\
Empleo en construcción $<15 \%$ e incidencia muy intensa del desempleo & 232.027 \\
\hline
\end{tabular}

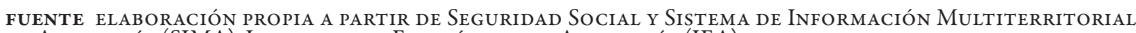
DE ANDAlucía (SIMA), Instituto de Estadística de ANDALucía (IEA).

\section{Discusión}

A partir de los resultados anteriormente expuestos, la discusión se centra en torno a cuatro ejes de debate fundamentales:

En primer lugar, hasta qué punto puede considerarse el caso español como una singularidad en el contexto europeo y mundial, ante el comportamiento y magnitud alcanzada por el sector de la construcción. A partir de los datos ofrecidos, se considera que, pese a que pueden existir similitudes con otros países, como es el caso de Irlanda (Norris \& Winston, 2010), no existe ningún otro ejemplo, al menos en Europa, en el que la construcción, y el subsector vivienda, hayan alcanzado los niveles cuantitativos y cualitativos del caso español. De esta forma, puede concluirse que el colapso del sector desde 2007 (a partir del estallido de la burbuja inmobiliaria, estancamiento del mercado de la vivienda y paralización de grandes recursos financieros en un elevado contingente de viviendas sin posibilidad de venta) otorga caracteres propios a la actual crisis de la economía y el empleo en España, haciendo especialmente difícil la salida de la misma.

En segundo lugar, desde un punto de vista metodológico, puede debatirse la utilidad de los indicadores estadísticos aquí utilizados para el análisis y seguimiento en el tiempo de la problemática tratada. Se estima demostrada dicha utilidad, al haberse realizado una selección de los mismos desde un enfoque multidisciplinar, combinando variables relativas a la orientación de la estructura productiva con otras pertenecientes al ámbito de la fiscalidad municipal, el mercado de la vivienda, la práctica del planeamiento urbano o la relación entre orientaciones productivas e incidencia 
de la crisis (todo ello condicionado por la disponibilidad de fuentes fiables, homogéneas y actualizables). Esta propuesta de indicadores puede lógicamente ampliarse según sea la información existente y la escala del ámbito de estudio elegido, pero resulta apta para los objetivos pretendidos y las escalas utilizadas en este artículo.

En tercer lugar, y como tema central de esta investigación, los resultados muestran las diferencias territoriales con las que se manifiesta la basculación de la economía y la sociedad españolas - y, más concretamente, andaluzas- hacia el sector de la construcción. De esta forma, la aplicación de indicadores a escala comarcal en el caso andaluz muestra las distintas intensidades que el fenómeno ha experimentado en las diferentes áreas del territorio regional. Como era previsible, las mayores magnitudes se registran en los espacios litorales y aglomeraciones urbanas, pero con la aparición de valores igualmente muy elevados en áreas serranas de notable calidad ambiental y en espacios prelitorales cercanos a los ámbitos turísticos consolidados. Ello representa una clara demostración de cómo este modelo económico-territorial, basado en la construcción y la urbanización, se ha extendido a amplias superficies del territorio andaluz, en algunos casos hacia áreas que habían permanecido ajenas al proceso hasta hace poco más de una década.

La discusión de mayor interés se centra en determinar si existe relación causal entre la intensidad de la orientación hacia la construcción y la gravedad de la crisis socioeconómica sufrida posteriormente, sobre todo a partir del indicador "Relación entre la incidencia laboral de la construcción (2006) y la evolución del desempleo a partir del estallido de la crisis (2006-2008)”. La conclusión más relevante extraída del análisis a escala territorial es la constatación de que existe una notable coincidencia entre las áreas en las que se registró una mayor intensidad del proceso constructivo y urbanizador, y aquellas que posteriormente han sufrido con mayor virulencia el impacto de la crisis (medido en el incremento de las tasas de desempleo). Se demuestra así que una excesiva basculación hacia el sector de la construcción conlleva una notable vulnerabilidad de las estructuras socioeconómicas locales (al margen de los costes territoriales y ambientales que dicha basculación implica).

Por último, y como reflexión de cara al futuro, cabe plantearse hasta qué punto las negativas consecuencias mostradas por el crecimiento desmesurado del proceso constructivo y urbanizador han sido interiorizadas y asumidas por los agentes sociales e institucionales de los territorios afectados. En efecto, pese a la evidencia de los datos, no parece percibirse una decidida voluntad de renunciar al sector de la construcción como motor de la economía y del empleo en las áreas que anteriormente se orientaron con mayor intensidad en ese sentido (como puede detectarse en la continuidad de la aprobación de planes urbanísticos muy expansivos en las áreas litorales). Por ello, no es descartable una revitalización de algunos de los procesos señalados en el caso de modificación de factores externos a lo local (mejora del escenario de financiación, recuperación de los mercados alemán y británico de demandantes de segundas residencias en España), con la debilidad sistémica a largo plazo que ello puede significar para las estructuras socioeconómicas y territoriales de los ámbitos implicados. OEURE 


\section{Referencias bibliográficas}

Banco de España. Informe Anual. [En línea] http://www.bde.es/webbde/es/secciones/informes/Pu blicaciones_an/Informe_anual/anoactual/

Banco de España (2009). Boletín Económico Febrero 2009.

Bernardos, G. (2009). Mercado residencial y necesidades de vivienda: situación actual y perspectivas de futuro. En C. Sambricio \& R. Sánchez Lampreave (Eds.), La vivienda protegida. Historia de una necesidad (pp. 231-253). Madrid: Ministerio de la Vivienda/Asociación Española de Promotores Públicos de Vivienda y Suelo (AVS).

Caruana, J. (2005). Monetary policy, financial stability and asset prices. Banco de España. Documentos ocasionales, n. $^{\circ} 0507$.

Cuadrado Roura, J. R. (Dir.). (2010). El sector de la construcción en España. Madrid: Colegio Libre de Eméritos.

Dol, K. \& Haffner, M. (2010). Housing Statistics in the European Union. La Haya: Ministry of the Interior and Kingdom Relations/OTB Research Institute for the Built Environment, Delft University of Technology.

Englund, P. \& Ioannides, Y. M. (1997). House price dynamics: an international empirical perspective. Journal of Housing Economics, 6(2), 119-136. http://dx.doi.org/10.1006/jhec.1997.0210

Fernández Durán, R. (2006). El tsunami urbanizador español y mundial. El Ecologista, 48, 20-24.

Fernández-Tabales, A. \& Mendoza, A. (2007). La actividad turística en el territorio andaluz. Establecimiento de indicadores, distribución y evolución de los mismos. Boletín de la Asociación de Geógrafos Españoles, 44, 117-146.

García-Bellido, J. (2005). Por una liberalización del paradigma urbanístico español (III). El tsunami urbanístico que arrasará el territorio. Ciudad y Territorio: Estudios territoriales, 144 273-288.

García-Montalvo, J. (2009). Financiación inmobiliaria, burbuja crediticia y crisis financiera. Lecciones a partir de la recesión de 2008-09. Papeles de Economia Española, 122, 66-87.

García-Montalvo, J. \& Mas, M. (2000). La vivienda y el sector de la construcción en España. Valencia: Editorial CAM (Caja de Ahorros del Mediterráneo).

Hamnett C. (2009). The Madness of Mortgage Lenders: Housing finance and the financial crisis. Londres: Institute for Public Policy Research (IPPR). En http://www.ippr.org/images/media/ files/publication/2011/05/madness_of_mortgage_lenders_1692.pdf

Instituto Nacional de Estadística (INE). (2001). Censo de población y viviendas 2001. Madrid: Instituto Nacional de Estadística/Ministerio de Economía y Hacienda.

Instituto Nacional de Estadística (INE). (2005). Encuesta de condiciones de vida 2005. Madrid: Instituto Nacional de Estadística/Ministerio de Economía y Hacienda.

Instituto Nacional de Estadística (INE). (2007). España en cifras 2007. Madrid: Instituto Nacional de Estadística/Ministerio de Economía y Hacienda.

Instituto Nacional de Estadística (INE). (2009). España en cifras 2009. Madrid: Instituto Nacional de Estadística/Ministerio de Economía y Hacienda.

Kim, K. (1999). Korea. Could a Real Estate Price Bubble Have Caused the Economic Crisis? Documento de Trabajo. Seúl: Sogang University. Publicado en K. Mera \& B. Renaud (Eds.), Asia's Financial Crisis and the Role of Real Estate (pp. 99-114). Armonk, NY: M. E. Shape, 2000. 
Leal, J. (2007). La política de vivienda en España. Documentación Social, 138,.63-80.

Malpezzi, S. \& Wachter, S. (2005). The role of speculation in real estate cycles. Journal of Real Estate Literature, 13(2), 143-166.

Meen, G. (1996). Ten propositions in UK housing macroeconomics: An overview of the 1980s and early 1990s. Urban Studies, 33(3), 425-444. doi: 10.1080/00420989650011843

Ministerio de Fomento de España. Estadísticas [base de datos en línea]. En http://www.mviv.es

Ministerio de Fomento de España (2007). Construcción de Edificios (2001-2006) Licencias municipales de obras. Madrid: Dirección General de Programación Económica, Subdirección General de Estadísticas y Estudios.

Ministerio de Fomento de España (2011). Informe sobre el stock de vivienda nueva 2010. Madrid: Dirección General de Programación Económica; Subdirección General de Estadísticas y Estudios.

Ministerio de la Vivienda (2009). Estadísticas [base de datos en línea]. En: http://www.fomento.gob. es/MFOM/LANG_CASTELLANO/ESTADISTICAS_Y_PUBLICACIONES/INFORMACION_ESTADISTICA/Vivienda/Estadisticas/Stock/default.htm

Murray, I., Rullán, O. \& Blázquez, M. (2005). Las huellas territoriales de deterioro ecológico. El trasfondo oculto de la explosión turística de Baleares [en línea]. Scripta Nova, 9(199) (15 de octubre de 2005). Universidad de Barcelona. En http://www.ub.es/geocrit/sn/sn-199.

Naredo, J. (2002). El patrimonio de los hogares españoles. Bolsa de Madrid, 108, 11-19.

Naredo, J. (2004). Perspectivas de la vivienda. ICE. Consecuencias de la evolución demográfica en la economía, 815 (mayo-junio), 143-154.

Naredo, J. (2006). Mitos inmobiliarios de nuestro tiempo. El Ecologista, 46 (invierno 2005/2006).

Naredo, J. M., Marcos, C. \& Carpintero, O. (2004). El patrimonio financiero-inmobiliario de los hogares españoles. Bolsa de Madrid, 127, 12-20.

Nasarre, S. (2011). Acceso a la vivienda en un contexto de crisis. Madrid: Editorial Edisofer S. L.

Norris, M. \& Winston, N. (2010). Second-home owners: escaping, investing or retiring? Tourism Geographies, 12(4), 546-567. doi: 10.1080/14616688.2010.516401

Ocaña, C. (2009). Urbanización y vivienda, negocio financiero y conflicto social. En Territorios, sociedades y políticas (pp. 349-368). Sevilla: Universidad Pablo de Olavide/Asociación de Geógrafos Españoles.

Observatorio de la Sostenibilidad de España (OSE). (2009). Informe Anual de la Sostenibilidad de España. Madrid: Autor.

Otrok, C. \& Terrones, M. (2005). House prices, interest rates and macroeconomic fluctuations: international evidence. Conferencia: Housing, Mortgage Finance and Macroeconomics. Banco de la Reserva Federal de Atlanta.

Parejo Alfonso, L. (2007). Condiciones básicas de igualdad de los ciudadanos y régimen básico del suelo en la Ley del Suelo. Ciudady Territorio. Estudios territoriales, 39(152-153), 311-360.

Pareja-Eastway, M. \& Sánchez-Martínez, M. T. (2011). El mercado de vivienda en España: la necesidad de nuevas propuestas. En Acceso a la vivienda en un contexto de crisis (pp. 31-49). Madrid: Edisofer.

Requejo, J. (2005). El problema del urbanismo. El tsunami de los climáticos. Diario El País, 20/12/2005.

Rodríguez López, J. (2007). Urbanismo, vivienda y economía en España. Revista ACE, 1(3), 83-88. 
Rodríguez López, J. (2009). La crisis de los mercados inmobiliario e hipotecario. Factores explicativos. Papeles de Economía Española, 122.

Servicio de Estudios de "La Caixa" (2003). La expansión del mercado de la vivienda en los últimos años. Barcelona: Autor.

Shiller, R. (2008). The Subprime Solution: How today's global financial crisis happened, and what to do about it. Princeton, NJ: Princeton University Press.

Instituto de Estadística de Andalucía, Consejería de Economía y Hacienda, Sistema de Información Multiterritorial de Andalucía. http://www.juntadeandalucia.es:9002/sima/index.ht.

Stevenson, S. \& Young, J. (2006). Comportamiento especulativo en los mercados de la vivienda: una perspectiva internacional. Papeles de Economía Española, 109, 14-26.

Taltavull de la Paz, P. (2006). La oferta de viviendas y el mercado inmobiliario en España. Papeles de Economía Española, 109, 156-181.

Taltavull de la Paz, P. (2010). El sector de la construcción y el mercado de la vivienda: del valle a la recuperación. Revista Economistas, 28(123), 88-99.

Vera, F. (2005). El auge de la función residencial en destinos turísticos del litoral mediterráneo: entre el crecimiento y la renovación. Papers de Turisme, 37-38, 95-114.

Whitehead, C. (2006). Una perspectiva internacional de los mercados de la vivienda. Papeles de Economía Española, 109, 2-13.

Zoido, F. (Coord.). (2001). Informe de Desarrollo Territorial de Andalucía. Sevilla: Secretariado de Publicaciones de la Universidad de Sevilla/Fundación Sevillana-Endesa / Caja Granada.

Zoido, F. \& Caravaca, I. (Coords.). (2005). Andalucía. Segundo Informe de Desarrollo Territorial. Sevilla: Secretariado de Publicaciones de la Universidad de Sevilla/Agencia de Innovación y Desarrollo de Andalucía/Fundación Sevillana-Endesa. 